\title{
Correlation and
}

Analysis of

Water-Temperature

Data for Oregon Streams

GEOLOGICAL SURVEY WATER-SUPPLY PAPER 1819-K

Prepared in cooperation with:

Oregon State $W$ ater Resources Board

U.S. Bureau of Reclamation

U.S. Army Corps of Engineers

U.S. Public Health Service

U.S. Soil Conservation Service

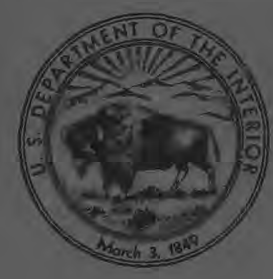




\section{Correlation and}

\section{Analysis of}

Water-Temperature

Data for Oregon Streams

By A. M. MOORE

CONTRIBUTIONS TO THE HYDROLOGY OF THE UNITED STATES

GEOLOGICAL SURVEY WATER-SUPPLY PAPER 1819-K

Prepared in cooperation with:

Oregon State Water Resources Board

U.S. Bureau of Reclamation

U.S. Army Corps of Engineers

U.S. Public Health Service

U.S. Soil Conservation Service

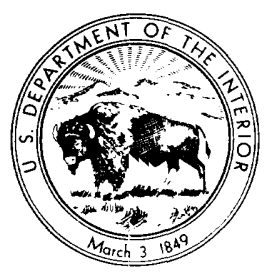




\title{
UNITED STATES DEPARTMENT OF THE INTERIOR
}

STEWART L. UDALL, Secretary

\author{
GEOLOGIGAL SURVEY \\ William T. Pecora, Director
}

For sale by the Superintendent of Documents, U.S. Government Printing Office Washington, D.C. 20402 


\section{CONTENTS}

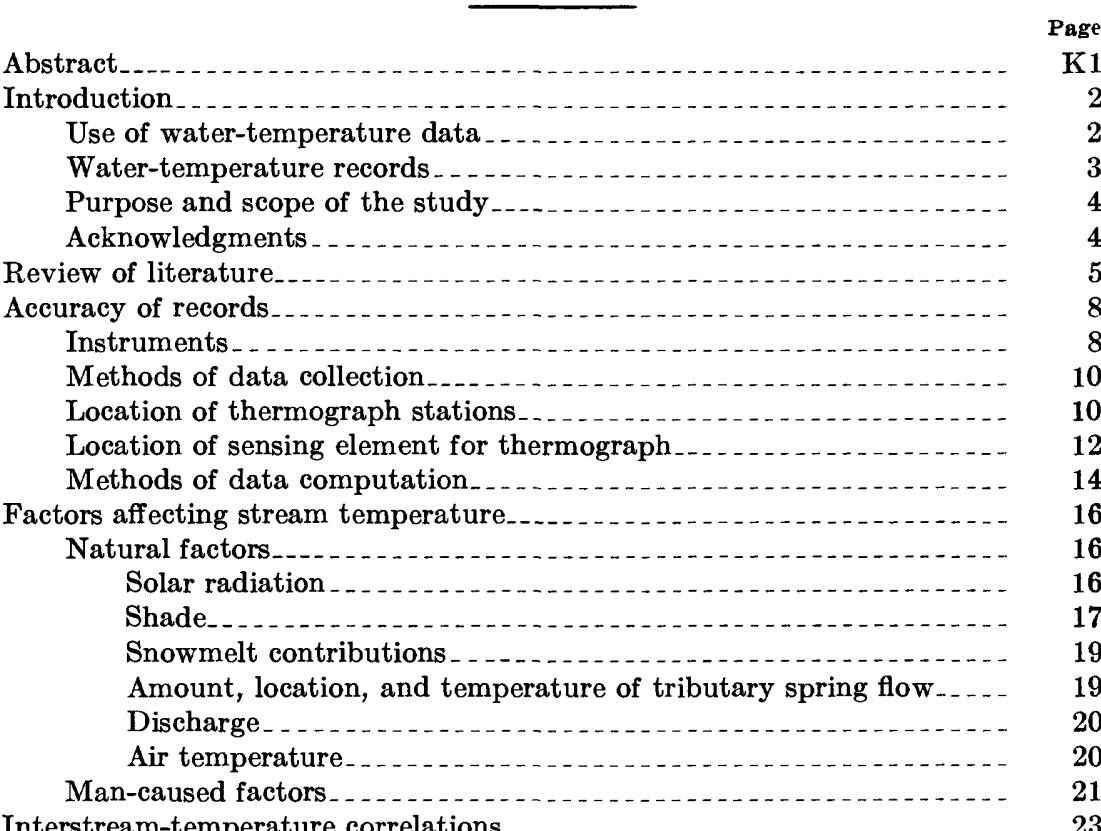

Interstream-temperature correlations............................ 23

Attempt to correlate spot observations of water temperature with air

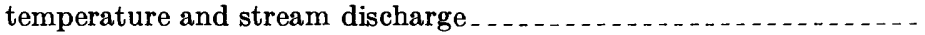

Correlation of spot observations of water temperature with thermo-

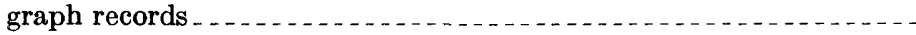

Test of effectiveness of correlation procedures . . . .

Effect of reservoirs on downstream water temperature

Inflow and outflow records............... 33

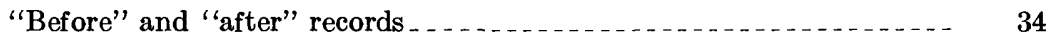

Variability of water temperature _...

Numerical scale for appraising short-term thermograph records _.... $\quad 39$

Test of numerical classification scale . . . . .

Statistical method for appraising monthly maximum and minimum water temperatures

Diurnal fluctuation of water temperature

Conclusions

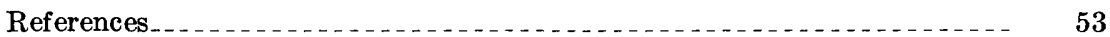




\section{ILLUSTRATIONS}

Plate 1. Map showing sites where water-temperature data have

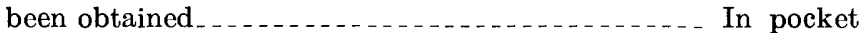

Figure 1. Photograph of water-stage recorder with thermograph attachment. ................................ K9

2. Sketch of typical gaging station $\ldots \ldots \ldots$

3-10. Graphs:

3. Temperature profile for Breitenbush River above Canyon Creek near Detroit on July 16, 1963 .

4. Correlation of monthly extremes of water temperature of Fall Creek near Alsea with corresponding water temperatures of Five Rivers near Fisher and Drift Creek near Salado......

5. Comparison of monthly mean air and water temperatures for selected east-west o-iented streams... . . . . . . . . . . . . . . . . . . . . . . .

6. Comparison of monthly mean air and water temperatures for selected spring-fed or northsouth oriented streams.

Page Typical water-temperature correlations showing a seasonal variation and a constant relation between spot observations and a thermograph record .

8. Water-temperature classification for central Oregon for July and August, 1931-62, based on air temperature at Bend and flow cf Lake Creek near Sisters

9. Test of water-temperature classification indices for July and August....................

10. Typical summertime diurnal fluctuation of water

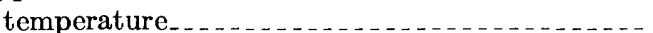

\section{TABLES}

TABLE 1. Comparison of water temperatures at inlet with those in nearby stream cross sections . . . . . . . . . . . . . . . . .

2. Comparison of errors in observed and adjusted water temperatures...................................

3. Effect of reservoirs on downstrearn water temperatures . -

4. Numerical classification of water temperature . .......

5. Recurrence intervals for period-of-record monthly maximum and minimum water temperatures for Desolation Creek near Dale and Middle Santiam River at mouth near Foster.

6. Maximum diurnal fluctuation of water temperature at thermograph sites 


\title{
CONTRIBUTIONS TO THE HYDROLOGY OF THE UNITED STATES
}

\section{GORRELATION AND ANALYSIS OF WATER-TEMPERATURE DATA FOR OREGON STREAMS}

\author{
By A. M. Moore
}

\begin{abstract}
The increasing demand for water-temperature data for Oregon strec.ms led to a compilation by the GeologicaI Survey of aImost aII such data coIIented by various agencies. These data were released in November 1964 in an open-file report. At some sites continuous records of temperature were obtained by means of a thermograph, but at most sites spot (periodic) measurements were made with a hand thermometer. The present report describes the deve'opment of procedures whereby spot observations of water temperature can be correlated with a representative thermograph record to estimate monthIy means and extremes at the site where the spot observations were made. In general, these synthetic figures represent probable water temperatures at the spot-observation site during the period of record for the thermograph site. Tests indice te that the average errors in the estimates of monthly means and extremes are about $1^{\circ}$ and $2^{\circ} \mathrm{F}$., respectively.
\end{abstract}

The correlations lead to some interesting findings concerning factors affecting water temperature. During the summer months, east-west orientation of a stream can resuIt in water temperature $4^{\circ}-8^{\circ} \mathrm{F}$. warmer than in a similar stream with north-south orientation. Longer exposure to direct solar radiation is the probable cause of this difference. AIso, the correlations are found to be a valuable tool in assessing the effect of reservoirs on downstream water temperatures.

The accuracy of the instruments and the methods used by the GenIogical Survey result in water-temperature records that are considered to be cccurate within $\pm 1^{\circ} \mathrm{F}$. A series of tests in the summer of 1963 showed that th? water temperature at the probe end of the thermograph is cIosely representative of the mean temperature of the stream cross section if the probe is in moving water.

Because water temperature in a given month varies from year to year, two rough guides are developed to assist in appraising short-term records with respect to long-term means and extremes of water temperature. One of these guides is a numerical scale that rates mean water temperature for all Julys and Augusts from 1913 to 1962 . The scale ranges from one to six : one represents the cold end and six the warm end. Another guide is a statistical device for determining probable recurrence intervals of certain maximum and minimum water temperatures. Both of these guides indicate that any western Oregon thermograph 
record that includes the cold summer of 1955 and the warm summer of 1958 contains extremes that represent at least 25-year events.

During the summer months, water temperature varies considerably even during one day. The amount of diurnal fluctuation can be significant and, in natural streams, depends largely on the amount of solar radiation absorbed, the amount of water to be warmed or cooled, and the amount and location of contributory spring flow. The maximum diurnal fluctuation at 129 thermograph sites is shown in tabular form. This listing can be used to estimate maximum diurnal fluctuation of water temperature in streams for which no thermograph records are available.

\section{INTRODUCTION}

\section{USE OF WATER-TEMPERATURE DATA}

The temperature of the water in a stream is as important for many uses as the rate of flow of water. To date (1966), industrial use of stream water for cooling purposes has been relatively minor in Oregon. In other parts of the country, water in some streams is us?d as many as 20 times, with the result that stream temperatures at times exceed $100^{\circ} \mathrm{F}$. However, many irrigation and hydroelectric dams have been built or are being planned in Oregon, and these can significnntly affect water temperatures. Steam powerplants will be necessary in a few years when all feasible hydroelectric powersites have been developed. General industrial use of stream water as a coolant will al o increase. Therefore, the temperature of streams in their natural state should be determined so that manmade changes can be readily identified and evaluated.

Fishery agencies are vitally interested in water temporatures in relation to the selection of hatchery sites or the development of spawning areas to replace some that may be lost through the building of hydroelectric power dams. Agencies concerned with building dams need water-temperature records before and after their construction activities to show the effect of the structures on water temperature.

Moore $(1957$, p. 9) reported that water-temperature records are useful in the computation of discharge records on many streams because they provide a guide as to when the stage-discharge relation becomes ice affected or when this effect may be increasing or decreasing.

Records are needed to gain a better understanding of the factors affecting water temperature. Only through such understanding can problems such as the effect of reservoir regulation on water temperature be accurately solved.

Many uses of water-temperature records may arise which have not as yet been considered. For years, water from wells has been used to heat buildings in winter and cool them in summer. Water from some streams could be used for this purpose if it, like ground water, were cooler than air in summer and warmer than air in winter. For 
example, spring-fed streams or reaches of rivers just below power dams where the water is released from the bottom of reservoirs contain water that is relatively uniform in temperature throughout the year. Water-temperature records serve to identify streams that could be used for heating or air conditioning and provide the necessary data for economical design of the equipment to be used.

\section{WATER-TEMPERATURE RECORDS}

The Geological Survey and other agencies have been collecting information on stream temperatures in Oregon since about 1947. Tr 9 Survey began collecting detailed information on streamflow more than 60 years ago, but the amount of stream-temperature data gathered prior to 1947 was negligible. The Oregon State Game Commission began 25 or 30 years ago to record water temperatures of streams supplying water to fish hatcheries, and the city of Portland began even earlier to record the temperatures of municipal water supplies.

In 1947 the Geological Survey began to record water and air temperatures at the time of visits to most gaging stations. The impetus for this program was provided by growing concern for the effect that increasing releases of municipal and industrial waste would have on public welfare and on fish life. These periodic readings, designated as spot observations and spaced 5 or 6 weeks apart, were inadequate because the water temperature might vary several degrees from the observed temperature even on the day of observation. However, these readings were better than none. For example, if a stream were being considered as a possible site for a hatchery where water temperature should never exceed $72^{\circ} \mathrm{F}$., spot observations of $76^{\circ} \mathrm{F}$. would $\mathrm{F}$ "ovide sufficient proof that the stream was not suitable for that purpose.

The U.S. Geological Survey, U.S. Fish and Wildlife Service, Oregon State Fish Commission, Oregon State Game Commission, and U.S. Army Corps of Engineers began about 1949 to collect thermograph records of water temperature at a few sites. This program las expanded to the extent that at the end of 1962 thermograph records had been obtained at 129 sites. Some of these records are for periods only a few months to a year in length, but many are for a period of 5-12 years. At the same time, the spot-observation program was continued by the Geological Survey, and the State Sanitary Authority began to make such observations at many sites. Plate 1 identifies 379 sites in Oregon where water-temperature data have been systematically collected.

Because of the widespread and growing interest in stream temperatures in Oregon, the Geological Survey has compiled all sigrificant water-temperature data that have been collected in the State by all 
agencies, both public and private. The data were released in November 1964 in an open-file report (Moore, 1964). An analytical study was considered essential to insure that all compiled data were expressed in meaningful form and to assist in the appraisal and use of that data. This report presents the findings of that analytical study.

\section{PURPOSE AND SCOPE OF THE STUDY}

The two main purposes of this report are (1) to describe methods developed for correlating temperature records collected at spot-observation sites with thermograph records from other sites so that the monthly means and extremes at the spot-observation sites can be estimated more accurately than on the basis merely of the periodic readings and (2) to appraise factors affecting water temperature. An incidental purpose of this report is to acquaint users of water-temperature records with the instruments and methods used to obtain the records.

The study was confined to Oregon streams and largely to the period 1947-62. Although records were kept for all months of the year, emphasis was placed on water temperatures recorded during the summer months because high temperatures and concurrent low flows intensify pollution problems and act as deterrents to fish runs.

The methods used in Oregon and the findings reported may well be generally applicable elsewhere. Certainly, the "Reviev of Literature" section of this report clearly indicates that the water-temperature pattern of Oregon streams is similar to that of streams in many other States.

\section{ACKNOWLEDGMENTS}

Agencies from whom receipt of water-temperature data is gratefully acknowledged are: U.S. Fish and Wildlife Service, U.S. Bureau of Commercial Fisheries, U.S. Army Corps of Engineers, Oregon State Game Commission, Orègon State Sanitary Authority, Oregon State Fish Commission, city of Corvallis, city of Portland, Eugene Water and Electric Board, Portland General Electric Co., and RoseburgOregon Water Corp. Leupold and Stevens Instruments Co. furnished the photographs showing details of the thermograph attachment for water-stage recorders. Special thanks go to Loren B. Thompson, who made the correlation studies for most of the spot-observation sites and gave helpful suggestions and criticisms. The report was prepared under the general supervision of Roy B. Sanderson, district engineer in charge of surface-water investigations in Oregon. 


\section{REVIEW OF LITERATURE}

Few reports on water temperature have been published. Beginning in 1943, however, the U.S. Geological Survey began collecting water-temperature data throughout the country.

Collins (1925, p. 101) concluded: "The mean monthly temporature of a surface water at any place is generally within a few degrees of the mean monthly air temperature when the air temperature is above the freezing point. The maximum water temperature in any of the warmer months is usually from $2^{\circ}$ to $6^{\circ}$ higher than the mean monthly water temperature."

The second part of the statement by Collins is true in Oregon only for spring-fed streams. For other Oregon streams the maximum generally exceeds the mean for the month by $4^{\circ}-12^{\circ} \mathrm{F}$. Collins' statement may have been based on records derived from once-daily observations, and if so, the true maximums may have been missed by several degrees.

Mangan (1946, p. 9-10), in discussing water temperature in Pennsylvania, stated:

Although the range in water temperature during the year will not vary as greatly as the air temperature over the same region, surface-water temperatures sometimes will range from the freezing point to 80 or more degrees Fahrenheit. As should be expected, water temperatures uniformly rise at a slower rate in the spring, and uniformly fall at a slower rate in the late summer and autumn, than air temperature. During months when the air tempersture is above the freezing point, and artificial influence is not prevalent, tl : mean monthly air temperature is a reasonable index as to the probable mean monthly temperature of the surface water. Normally, however, the mean monthly temperature of the water, from May through November, will slightly exceed the monthly air temperature of the region.

Both air and water temperatures in any region in Pennsylvania are usually at their maximum during July when the mean water temperature may exceed the mean air temperature by as much as $8^{\circ}$. The maximum daily water temperature during July will generally average $5^{\circ}$ to $8^{\circ}$ above the mean monthly water temperature for that month.

Mangan's conclusions apply to Oregon as well as to Pennsylvania, but with some exceptions. First, it cannot be said that the mean monthly temperature of Oregon streams will normally slightly exceed the monthly air temperature of the region. As in Pennsylvania, there are some streams whose mean monthly water temperatures during the summer do exceed mean monthly air temperature, but there are many whose water temperatures are significantly lower than air temperature. Generally, the mean monthly temperatures of those streams that are exposed to much direct sunlight tend to exceel mean monthly air temperatures, which, of course, are taken in the shade. The mean monthly temperatures of streams that are largely spring fed 
generally are lower than the mean monthly air temperature, as are those of streams where exposure to direct sunlight is minimized by a north-south orientation and by wooded banks.

Mangan's finding that maximum water temperatures during summer months generally exceed mean monthly water temperature by $5^{\circ}-8^{\circ} \mathrm{F}$ (as compared with Collins' $2^{\circ}-6^{\circ} \mathrm{F}$.) is more nearly in line with conditions in Oregon. Mangan, too, might have found a greater difference if he had been able to work with thermograph records rather than with spot-observation records.

Some findings by previous investigators with respect to obtaining daily mean water temperatures can be summarized as follcws: Meyer (1928, p. 21-22) found that when twice-daily spot observations of water temperature are used, an average of those obtained at 9 a.m. and 9 p.m. give the best estimate of the daily mean water temperature. D. Q. Matejka (oral commun., 1951), in discussing Nebraska streams, concluded that two or three daily temperature observations-morning and evening or morning, noon, and night-best define the daily mean water temperature. He further concluded that observations at 8 a.m. and $4 \mathrm{p} . \mathrm{m}$. are the most practical and, when averaged, define a temperature that is within 2 percent of the true mean. W. A. James (oral commun., 1951) tested 10 different methods for computing daily mean water temperature of New Mexico streams and concluded that averaging the maximums and minimums for each day produced sufficiently accurate results, with a probable error of $0.57^{\circ} \mathrm{F}$.

Figure 10 indicates that minimum water temperature usually occurs between 7 a.m. and 10 a.m.; maximum, between 3 p.m. and 6 p.m. For Oregon streams, twice-daily observations of water temperature, obtained at 7 a.m. and 5 p.m. or at 8 a.m. and 4 p.m., would give a good approximation of maximum and minimum, as well as mean, temperature.

\section{Sylvester (1963,p. 6) stated:}

The natural temperature rise or fall of a water body is established by a number of meteorological and physical factors. Meteorological factors infiuencing water temperature are the amount of solar radiation, wind velocity, air temperature and vapor pressure. Physical factors are the surface area exposed, water depth, water temperature, rate of water exchange, mixing afforded, shadin $:$ from vegetation or land masses, impurities in the water, surface and subsurface infiows, and the temperature of the surrounding land mass. The most important factor is the amount of solar radiation absorbed, which for a given mass of water is a function of the exposed water surface area.

Sylvester $(1963$, p. 15,17$)$ concluded:

The impoundment of water will produce various temperature efects on the impounded water temperature and on the downstream water temperature, depending upon:

1. Volume of water impounded in relation to mean streamfiow. 
2. Surface area of impounded water.

3. Depth of impounded water.

4. Orientation with prevailing wind direction.

5. Shading afforded.

6. Elevation of impoundment.

7. Temperature of inflow water in relation to temperature of impounded water.

8. Depth of water withdrawal.

9. Downstream flow rates during critical temperature period, i.e., an increase or decrease in flow over that occurring naturally.

In general, it can be said that large and deep impoundments will decrease downstream water temperatures in the summer and increase them in the winter, if withdrawal depths are low; that shallow impoundments with large surface areas will increase downstream water temperatures in the summer; that water periodically withdrawn from the surface of a reservoir will increase downstream water temperatures; that a reduction in normal streamflow below an impoundment will cause marked temperature increases; and that "run-of-river" impoundments, when the surface area has not been markedly increased over the normal river area, will produce only small increases in downstream water temperatures.

Results found in studying water temperature of Oregon streams tend to support Professor Sylvester's statements. Probably items 1, 3, 8, and 9, as listed by Professor Sylvester, are those having the most effect on stream temperature downstream from the reservoir.

Ward (1963, p. 13) concluded:

An empirical equation, Eq. 1, has been found that closely fits the annual variation of temperature in a stream. The annual average temperature of a stream $\bar{T}$ apparently does not vary appreciably from year to year. In $\varepsilon$ ddition, the characteristics of the temperature sine curve $(a, c$, and $\bar{T})$ do not change materially from year to year.

The effect of introducing a reservoir on a stream can be summarized as follows: (1) $\bar{T}$ is reduced; (2) $a$ is reduced; (3) the absolute value of tr 9 phase coefficient of the sine curve, $c$, is increased; (4) the index of correlation is reduced ; and (5) the standard error of estimate is increased. All of these effects were expected.

Although this was not mentioned in his conclusions, Ward's work was confined to Arkansas streams.

During the work on this report, it was noted that monthy mean temperatures and monthly maximum and minimum temperatures of Oregon streams generally decreased from August to February and increased from February to August. In fact, correlations were rechecked when significant departures from this pattern were noted. Some Oregon streams follow a sine-curve pattern as closely as do Arkansas streams, but many depart markedly from a true sine curve.

1 $T=a \sin \left(b x+c+\bar{T}\right.$, in which $T$ is the temperature of the stream water, in ${ }^{\circ} \mathrm{F}$., $a$ is the amplitude of the sine curve, $b=\frac{360^{\circ}}{365 \text { days }}=0.987^{\circ}$ per day, $x$ is the numbe- of days since October $1(x=1$ for October 1$), c$ is the phase coefficient, and $T$ is the annuel average water temperature. 
In western Oregon the fall, winter, and spring are generally cloudy and cool (but not cold) and rain is frequent, but the summer months are generally warm and dry. These climatic conditions result in water temperatures which, when plotted on a graph, show a long shallow trough (November-May) below the annual mean water temperature, and a steep crest during the summer months of low flow.

Ward's conclusion that building a reservoir on a stream results in lower average annual water temperature downstream does not appear to be applicable in all instances in Oregon. Some reservoirs in western Oregon had the effect of raising the average annual water temperature downstream. (See section of this report on "Effect of Reservoirs on Downstream Water Temperature.") A rise in the annual water temperature can result if the reservoir is shallow or if water is drawn from near the surface during summer months.

\section{ACCURACY OF RECORDS}

\section{INSTRUMENTS}

Hand thermometers used by the Geological Survey are filled with red liquid and are graduated in $1^{\circ}$ intervals from $30^{\circ}$ to $110^{\circ} \mathrm{F}$. Initially, mercury-filled thermometers were used, but the red-liquid type is easier to read and is almost as accurate, although it is slower in responding to temperature change. Manufacturing practice permits errors of one-half the smallest graduation and, therefore, those used by the Geological Survey are rated accurate within $0.5^{\circ} \mathrm{F}$. Other agencies furnishing records for the compilation report use thermometers of similar accuracy.

The thermometers used by the Geological Survey in Oregon are tested for accuracy from time to time by comparing them with a laboratory-rated thermometer. Generally, accuracy within about $0.5^{\circ}$ $\mathrm{F}$. is found, and only rarely is the error $1^{\circ} \mathrm{F}$. or more.

The thermographs used by the Geological Survey in Oregon are attached directly to the water-stage recorder, so that the water temperature and stage are recorded on the same strip chart (fig. 1). These thermographs are rated by the manufacturer as accurate within $2^{\circ} \mathrm{F}$, but the record can be considered accurate within $1^{\circ} \mathrm{F}$. because hand-thermometer measurements are made at each visit to the station and, where necessary, corrections based on these readings were applied to the record. Experience in Oregon has shown that thermograph and hand-thermometer observations agree within $1^{\circ} \mathrm{F}$. about 80 percent of the time, and within $2^{\circ} \mathrm{F}$. about 95 percent of the time. This corresponds closely to the claimed accuracy for the thermograph. Weekly thermographs used in Oregon by other agencies are generally as accurate as those used by the Geological Survey. 
WATER-TEMPERATURE DATA FOR OREGON STREAMS

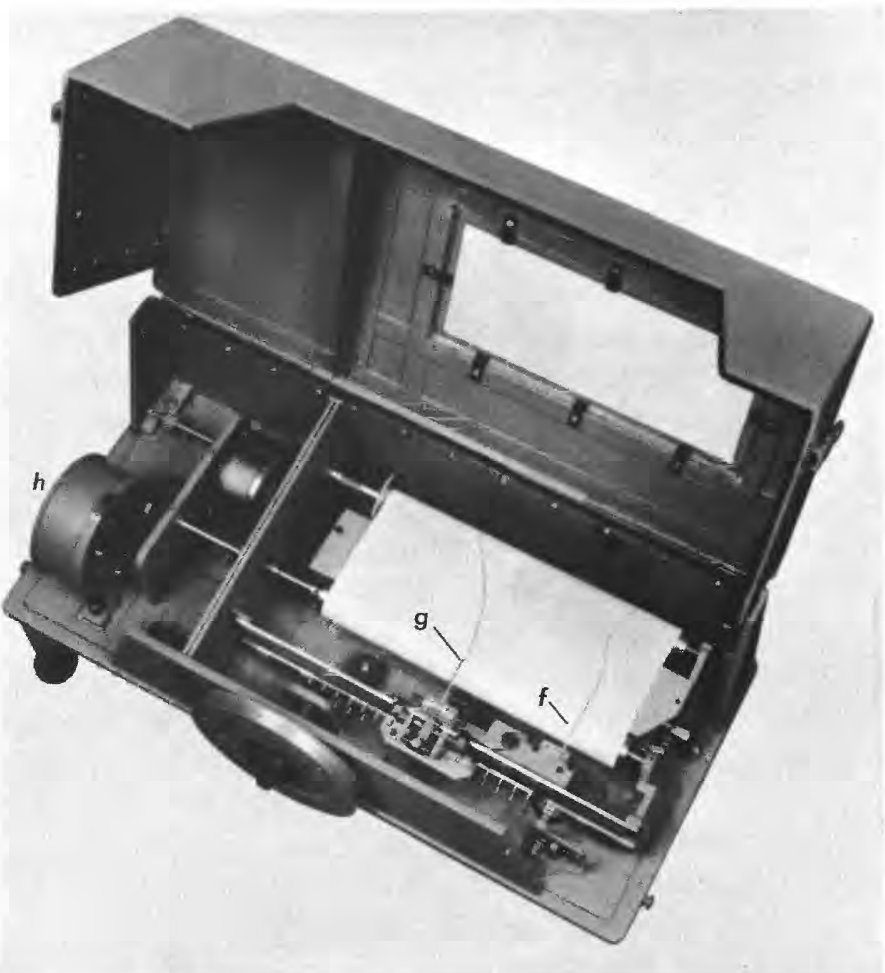

뭉

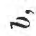

$\ddot{\Xi}$

:

胥

总

$\therefore \ddot{E}$

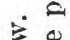

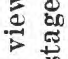

용

$+\infty$

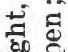

$\rightarrow$

...

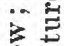

눈

$>$

ีㅡㅇ 명

옹옹

24

峞苍

苞宫

ن 0

吾..

눈

로 ซี

政

80

范

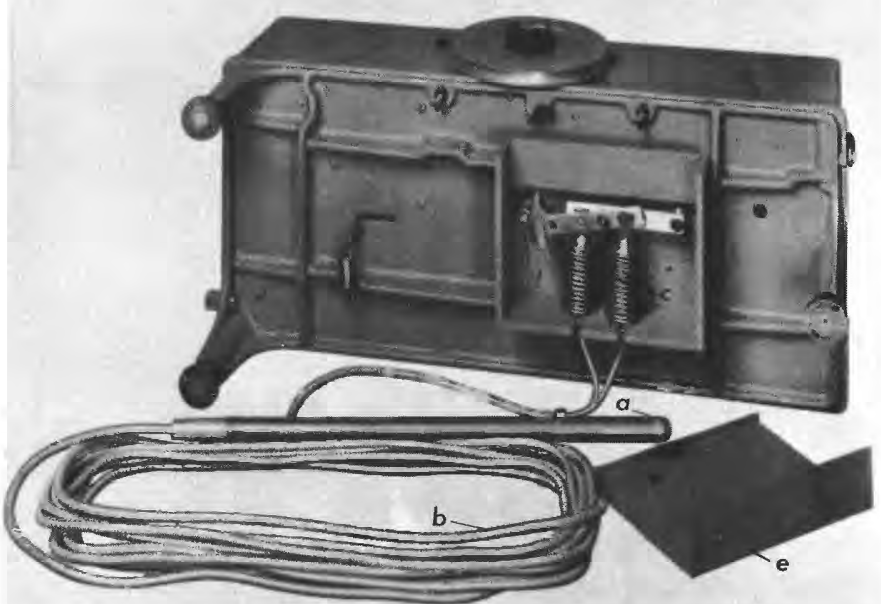

运

돈

.

造

है

¿

-

\&

.

4

ธิ

$\pm$

०

..

-i.

놀

른

온 


\section{METHODS OF DATA COLLECTION}

When spot-observation or thermograph sites are visited by Geological Survey personnel, hand-thermometer measurements are made of air and water temperatures, respectively. Air temperature (in the shade) is measured first so that there is no risk of obtaining an erroneously low air-temperature reading due to evaporation from a wet thermometer. Water temperature is then measured by holding the thermometer in moving water and reading the thermometer while the bulb end is immersed. At thermograph sites, the hand thermometer is held in moving water near the end of the inlet pipe containing the temperature probe.

Figure 2 is a sketch of a typical gaging station where both temperature and stage records are collected. When these temperature records were first collected, the temperature probe (bulb) and tubing were housed in one of the regular stage-inlet pipes. Experience soon showed that a separate inlet, slanting downward from the well to the water, was desirable. Use of the slanting inlet eliminated the need for a sharp bend in the tubing. Sharp bends sometimes kinked the tubing and made the thermograph inoperative. The slanting inlet also helped prevent sand and gravel from lodging in the inlet pipe. On regulated streams there is still another reason for having a separate temperature inlet. Water in the gage well can be several degrees warmer or cooler than that in the stream. Water leaving the gage well during a sharp regulated drop in stage can cause a temporary error in the temperature record if the temperature probe is housed in the stage-inlet pipe.

Most of the weekly type thermographs are housed in small hutchtype shelters or mounted in boxes attached to trees or posts. The probe is placed on the streambed, and the capillary tubing connecting the probe with the recorder may be completely exposed or may be placed in a shallow trench and then covered with earth. Erroneous temperature registration may result if the probe becomes covered with silt or gravel. Also, errors can result if the streamflow decreases to the extent that the probe becomes exposed to the air, or if the water surrounding the probe is no longer moving. However, such disadvantages need not be serious if thorough inspections are made each time the charts for these weekly recorders are changed.

\section{LOCATION OF THERMOGRAPH STATIONS}

Care must be exercised to locate thermographs far enough downstream from tributaries to ensure that the waters from the main stream and the tributary are completely mixed. Some thermographs operated by the Geological Survey have been added at existing stations whose sites had been selected without regard to their suitability for sampling 


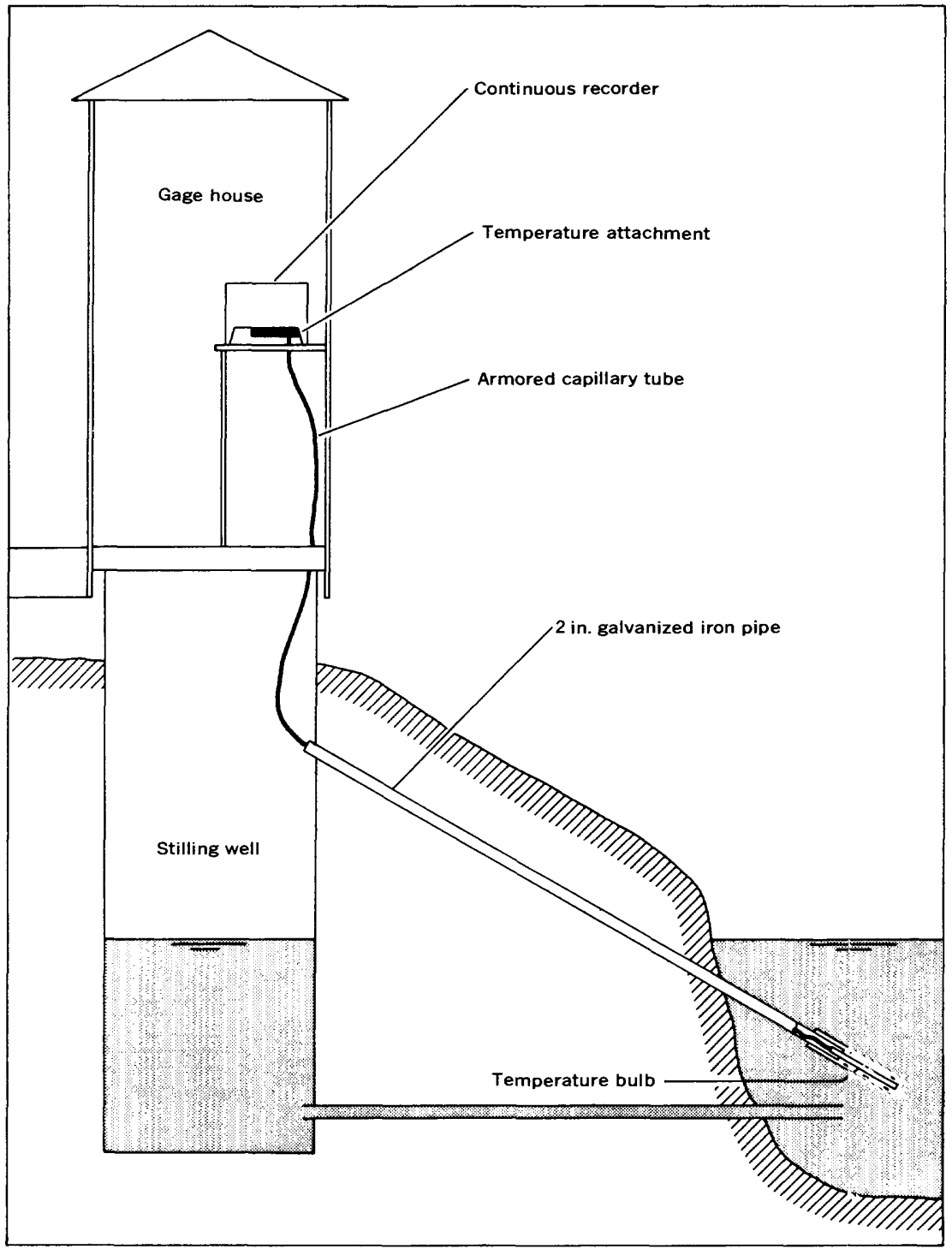

Frgure 2.-Typical gaging station where both stage and water-temperature records are obtained.

water temperature. Two thermograph stations established by the Geological Survey on the Grande Ronde River were unsatisfactory in this respect, and therefore the records have not been published and are not included in the open-file compilation report. The thermegraph on the Grande Ronde River at Troy was installed in the gaging station 
located 100 feet below the mouth of the Wenaha River. Later investigations showed that the waters were not completely mixed at this point, so that the record obtained was considerably different from one that would have been obtained above the Wenaha River or lalf a mile downstream. A similar condition existed at Grande Ronde River near Rondowa, where the station was 500 feet downstream from the Wallowa River. Observations made at the times of discharge measurements for about 8 or 9 years indicate that temperatures of the two streams are within $1^{\circ}$ or $2^{\circ} \mathrm{F}$. of each other except during June through August, when the Wallowa River may be $3^{\circ}-9^{\circ} \mathrm{F}$. colder than the Grande Ronde River because of snowmelt contributions. This serves to illustrate that checking the mixing of the main stream and tributary at just one season of the year may not be sufficient. If a temperature profile had been run at Rondowa in March or April, uniform temperatures across the stream would probably have been found, but another check in June or July might have disclosed that right-bank water was $6^{\circ} \mathrm{F}$. colder than left-bank water.

\section{LOCATION OF SENSING ELEMENT FOR THERMOGIPAPH}

When the U.S. Geological Survey began to use thermographs (1949), surface temperatures across the stream were measured with a hand thermometer to ensure that water temperature at the stream end of the inlet pipe housing the temperature probe was representative of that for the entire stream width. This was always found to be true. In later years a check to make sure that the temperature probe was submerged in moving water at all stages was considered sufficient. For this report, more conclusive evidence was sought to show that thermograph records obtained by the Survey are truly representative of the stream temperature.

In 1963 the Survey purchased a telethermometer, an instrument which permits measurement of water temperature at any decired depth. The temperature is read directly from the dial of a small console while the probe is stationed at the desired depth. The ronge of the telethermometer is from $30^{\circ}$ to $120^{\circ} \mathrm{F}$, and guaranteed accuracy is 1 percent of the range, or $0.9^{\circ} \mathrm{F}$. The telethermometer was used in the summer of 1963 to obtain temperature profiles at 40 thermograph stations. The results of these tests are shown in table 1. Figure 3 shows the temperature profile for Breitenbush River above Caryon Creek near Detroit. All water-temperature readings shown in table 1, including those at the inlet pipe, were taken with the telethormometer. Hand-thermometer readings were also made at the end of th 9 temperature inlet and were generally within $0.5^{\circ} \mathrm{F}$. of the telethermometer readings. 


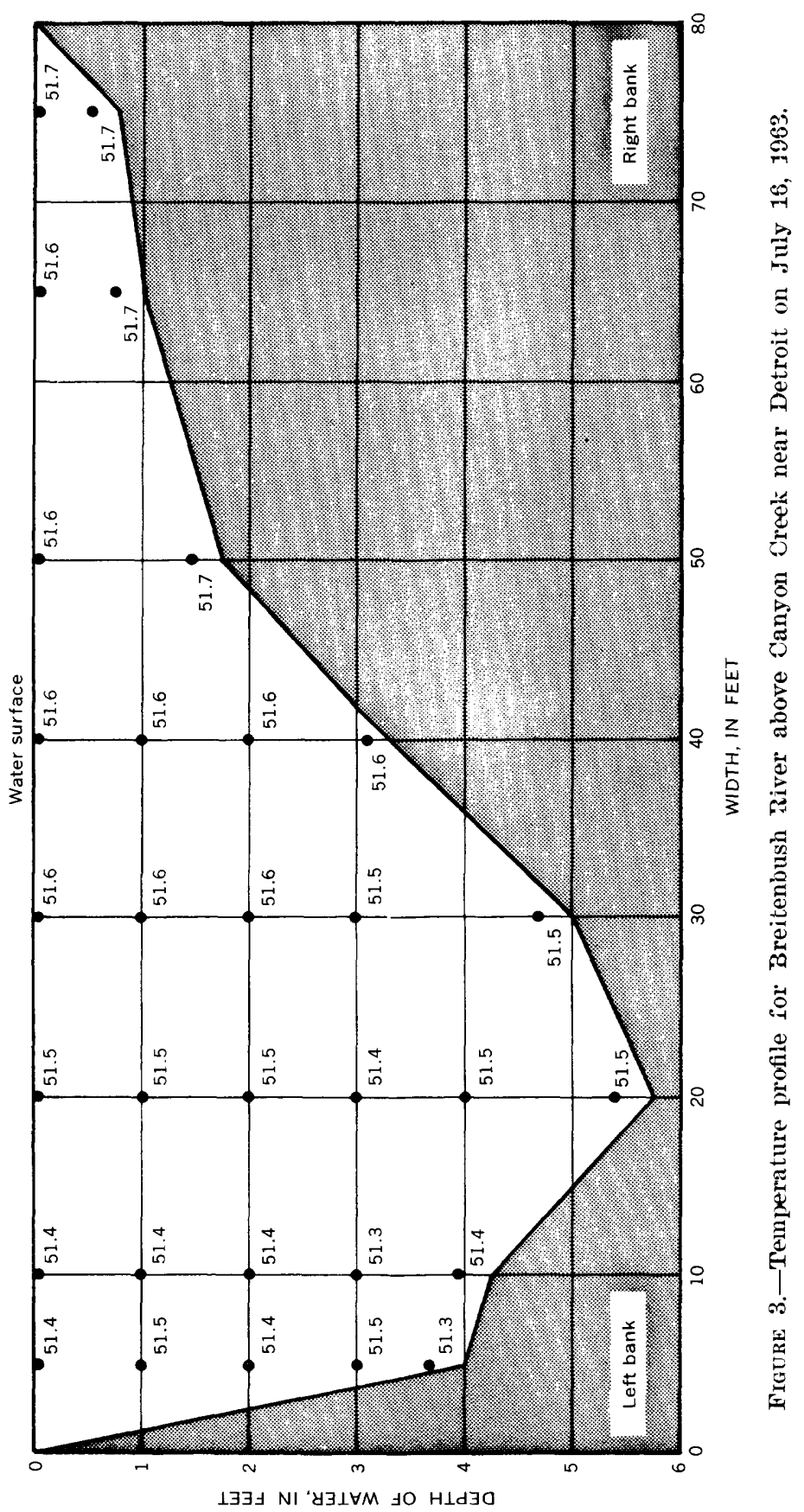


Table 1 shows that, for 38 of the 40 sites, temperature at the inlet was within $0.7^{\circ} \mathrm{F}$. of the average for the cross section, and for 29 sites, within $0.3^{\circ} \mathrm{F}$. The average for the cross section is a simple average of the observations; no attempt was made to weight by the amount of flow, as that refinement would have resulted in changes of less than $0.5^{\circ} \mathrm{F}$. in the averages. Temperature profiles could not always be taken exactly at the thermograph site, which may account for at least some of the differences found between temperatures at the inlets and the average temperatures for the cross sectiors at three stations on Middle Fork Willamette River (near Oakridge, above Salt Creek, and near Dexter) and at the station on Blue River near Blue River. Note that at those four sites the temperature at the inlet pipe falls outside the temperature range in the cross section. Three of those four sites were tested in 1962 for surface temperature across the stream, and those tests (not listed in this report) showed close agreement between temperature in the section and at the inlet. Table 1 also shows that at some sites there is as much as $3^{\circ} \mathrm{F}$. variation in temperature within the cross section, but in all instances this is caused by one or two observations of comparatively high temperatures near the bank where the flow is extremely sluggish. One example of this is Middle Fork Willamette River below North Fork near Oakridge, where the temperature in the cross section varied from $63^{\circ}$ to $60^{\circ} \mathrm{F}$, but the average was $60.5^{\circ} \mathrm{F}$, which was within $0.5^{\circ} \mathrm{F}$. of that at the inlet.

In summary, the tests indicate that the thermograph records are closely representative of the average temperature for the cross section and that there is little variation in the temperature of moving water in the cross section.

\section{METHODS OF DATA COMPUTATION}

Because the average of the maximum and minimum water temperatures for a day is a good estimate of the mean for the day, the Geological Survey has published only maximums and minimums for: each day and average maximums and minimums for each month for the thermograph records appearing in annual streamflow reports. As pointed out previously, the daily mean temperatures for New Mexico streams were found to have probable errors of only $0.57^{\circ} \mathrm{F}$. if obtained by averaging maximum and minimum temperature for the day. The thermograph traces in figure 10 indicate that the method is reasonably accurate for Oregon streams. If the maximum and minimum temperatures for a day can be averaged to give a good estimate of the daily mean, then average maximum and average minimum for a month can be averaged to give at least as good an estimate of monthly mean 
TABLE 1.-Comparison of water temperatures at inlet with those in nearty stream cross sections

\begin{tabular}{|c|c|c|c|c|c|}
\hline \multirow{2}{*}{ Station No. } & \multirow{2}{*}{ Station } & \multirow{2}{*}{ Date } & \multirow{2}{*}{$\begin{array}{l}\text { Water } \\
\text { tempera- } \\
\text { ture at } \\
\text { inlet } \\
\left({ }^{\circ} \mathrm{F} .\right)\end{array}$} & \multicolumn{2}{|c|}{$\begin{array}{l}\text { Water temperature } \\
\left.\text { in cross sijction ( }{ }^{\circ} \mathrm{F} .\right)\end{array}$} \\
\hline & & & & Average & Range \\
\hline 13-2867. & Powder River near Richland ...... & $-2-63$ & 70.5 & 70.5 & $71.3-70.0$ \\
\hline & Eagle Creek above Skull Creek, near N & & & 59.3 & $59.9-59.0$ \\
\hline & Grande Ronde River at La Grande... & & & 80.2 & $81.0-79.8$ \\
\hline & ostine River near Lostine & $8-8-63$ & 59. & 59.9 & $60.0-59$. \\
\hline & South Fork Walla Walla River near Milt & $8-13-63$ & 55.8 & 55.6 & $57.0-55.0$ \\
\hline & Umatilla River above Meacham Creek, $n$ & & 73. 0 & 73.1 & $73.5-73.0$ \\
\hline $14-0395$ & South Fork John Day River near Dayvill & $8-16-63$ & 62.6 & 62.3 & $62.8-62.0$ \\
\hline & $\begin{array}{l}\text { Desc } \\
\text { Desc }\end{array}$ & & & & 53.9 \\
\hline & 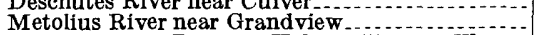 & $7-17-63$ & & & $51.6-51.5$ \\
\hline & Warm Springs River at Hehe Mill, near Warm & & & & \\
\hline & $\begin{array}{l}\text { Springs } \\
\text { Deschutes River at Moody, near Biggs }\end{array}$ & $\begin{array}{l}7-18-63 \\
7-18-63\end{array}$ & $\begin{array}{l}51.5 \\
66.1\end{array}$ & $\begin{array}{l}51.5 \\
65.7\end{array}$ & $\begin{array}{l}51.5-51.4 \\
66.6-65.2\end{array}$ \\
\hline & Gre & $7-18-63$ & & & 57. \\
\hline $14-1448$. & Middle Fork Willamette River near Oakridge.... & $9-9$ & & 156.7 & $57.0-56.5$ \\
\hline & $\begin{array}{l}\text { Hills Creek above Hills Creek Reservoir, near } \\
\text { Oakridge }\end{array}$ & & & & \\
\hline $14-1455$. & Middle Fork Willamette River above S & & 01. & 00.8 & 1,0 \\
\hline & near Oakridge & $9-9-63$ & 51.0 & 50.0 & $50.0-50.0$ \\
\hline $14-1480$. & Middle Fork Willamette River below North & & & & \\
\hline & $\begin{array}{l}\text { Fork, near Uakr1 } \\
\text { Middle Fork Willa }\end{array}$ & $9-11-63$ & $\begin{array}{l}60.0 \\
59.5\end{array}$ & $\begin{array}{l}60.5 \\
58.8\end{array}$ & $\begin{array}{l}63.0-60.0 \\
59.0-58.5\end{array}$ \\
\hline & & & & & \\
\hline & Midd & $9-1$ & & & 60. \\
\hline & River at London & $9-11-63$ & 65.0 & 65.0 & $65.0-65.0$ \\
\hline & Coas & 010 & & & \\
\hline 14- & $\begin{array}{l}\text { Horse Creek near McKenzie Bridge } \\
\text { South Fork McKenzie River ab }\end{array}$ & $9-10-63$ & 53.5 & 53.4 & $53.5-53.0$ \\
\hline & $\begin{array}{l}\text { South Fork Mckenzie River above Cou } \\
\text { Reservoir, near Rainbow }\end{array}$ & $9-10-63$ & 50.5 & 251.0 & 51.0 \\
\hline 14-1595. & South Fork McKenzie River near Rainbow.. & & & & 55.5 \\
\hline & & & & & 69. \\
\hline & River near Vida & $9-11-63$ & 51.0 & 51.0 & 51. 0-51. \\
\hline & North Santiam River below Boulder Creek, & & & & \\
\hline 14-1790. & $\begin{array}{l}\text { near Detrolt } \\
\text { Breitenbush River above Canyon Creek, near }\end{array}$ & & & & \\
\hline & & $\begin{array}{l}7-16-63 \\
7-16-63\end{array}$ & $\begin{array}{l}51.5 \\
46.2\end{array}$ & 51.5 & $\begin{array}{l}51.7-51.3 \\
46.5-45.8\end{array}$ \\
\hline 14-1850. & $\begin{array}{l}\text { am River at Niagara. } \\
\text { am River below Cascadia.. }\end{array}$ & $\begin{array}{l}7-16-63 \\
7-17-63\end{array}$ & $\begin{array}{l}40.2 \\
55.6\end{array}$ & 55.6 & $\begin{array}{l}46.5-45.8 \\
55.6-55.6\end{array}$ \\
\hline $14-1860$. & Middle Santiam River near Foster.... & $7-16-63$ & 61.5 & 61.5 & $61.5-61.5$ \\
\hline & Thomas Creek near Scio....... & $7-16-63$ & 60.2 & 60.2 & $60.2-60.1$ \\
\hline 14-3063. & Fall Creek near Alsea.... & $7-8-63$ & 55 & 55. 5 & $56-55$ \\
\hline $14-3064$ & Five Rivers near Fisher - & $7-8-63$ & & $57 . \mathrm{f}$ & $58-57$ \\
\hline $\begin{array}{l}14-3066 \text {. } \\
14-3067 .\end{array}$ & $\begin{array}{l}\text { Drift Creek near Salado- } \\
\text { Needle Branch near Salad }\end{array}$ & $\begin{array}{l}7-9-63 \\
7-9-63\end{array}$ & $\begin{array}{l}55.5 \\
53.5\end{array}$ & $\begin{array}{l}55.5 \\
53.5\end{array}$ & $\begin{array}{l}55.5-55.5 \\
53,5-53.5\end{array}$ \\
\hline $14-3068$ & Flynn Creek near Salado..... & $7-9-63$ & 52 & 52 & $52-52$ \\
\hline & Deer Creek near $\mathrm{S}$ & $7-9-63$ & 53 & 53 & $53-53$ \\
\hline & South Fork Coquille River near P & $8-27-$ & 65.0 & & \\
\hline & Rogue River near Agness & & 70.5 & 70.5 & $70.5-70.5$ \\
\hline
\end{tabular}

1 Cross section taken 600 feet upstream from gage house.

2 Cross section taken 1,300 feet downstream from gage house.

temperature. This was done in the open-file compilation report to obtain monthly mean temperatures shown for thermograph stations.

Maximum water temperature on any day cannot be less than the minimum water temperature on the preceding or following day, because the separation between adjacent days is infinitely small and the temperature cannot change instantaneously. To avoid this anomaly, many precautions must be taken in computing the records. Sometimes such errors occur if, for example, a recording of $54.5^{\circ} \mathrm{F}$. is rounded downward on one day to $54^{\circ} \mathrm{F}$. and a similar recording is rounded upward on the following day to $55^{\circ} \mathrm{F}$. The anomaly results most commonly at the beginning of a correction to the thermograph 
record where the maximum and minimum on one day are corrected and those on the preceding day are not corrected. The Geological Survey has found that beginning corrections at noon rather than at midnight aids greatly in eliminating these errors. When records are completed, Survey personnel make what is termed a "maximum-minimum test" to see that this anomaly does not exist. Despite these precautions, errors of this type occasionally go undetected. Such errors are usually no more than $1^{\circ} \mathrm{F}$., or within the accuracy of the record; but confidence in the record may be shaken if these anomalies are present and, especially, if the error is more than $1^{\circ} \mathrm{F}$.

\section{FACTORS AFFECTING STREAM TEMPERATURE}

In studies of heat budgets for lakes and reservoirs, the temperature of inflow and outflow streams is measured and the effect of solar radiation on the impounded water is computed. The relation between solar radiation and water temperature is complex, involving direct sunlight, reflected radiation, back radiation, heat advected from air to water (or vice versa), and heat consumed in evaporation processes. The last two items require measurements of windspeed and vapor pressure.

All factors affecting the heat budget of a lake or reser oir affect stream temperature, but there are many other factors to be considered, too. In general, these additional natural factors are the physical characteristics of the basin that tend to modify the effert of solar radiation. It is beyond the scope of this report to develop he $t$ budgets for Oregon streams. The concern here is simply to identify major factors affecting stream temperature and explain qualitatively why some streams are cooler or warmer than others.

\section{NATURAL FACTORS}

The major natural factors affecting stream temperature are solar radiation, shade, snowmelt contributions, tributary spring flow (amount, location, and temperature), discharge, and air ter.perature.

\section{SOLAR RADIATION}

Solar radiation is the chief factor affecting stream temperature. Therefore, the temperature of Oregon streams is at a maximum in the summer, when solar radiation is at a maximum, and at a minimum during the winter, when solar radiation is at a minimum. Solar radiation also influences some of the other factors affecting water temperature. For example, the release of snowmelt contrilutions to streams depends on solar radiation and air temperature, the latter depending largely on solar radiation. The length of a steeam is a measure of the time of exposure to solar radiation and air. During 
most of the year the water-temperature gradient is positive in a downstream direction. The temperature of spring-flow contributions to streams is affected by solar radiation over an extended period of time. That is, the temperature of the ground water approximates the mean annual air temperature of the region in which it occurs (Collins, 1925, p. 97 ; Mangan, 1946, p. 9). This, of course, is not true of s3-called thermal springs, such as those where the water comes from great depths and is warmed by the heat of the earth's core, those wh ore the water derives heat from buried lava, or those where the water is warmed by residual heat from faulting of the earth's crust. Reference to spring flow in this report will be confined to nonthermal springs because, in Oregon, thermal springs are too few to be significant.

\section{SHADE}

Wooded banks, steep canyon walls, landmasses, and north-south orientation can all provide shade for a stream. Of these, the northsouth orientation is most important, as the effect of the other three factors will be minimized if the stream runs in an east-west direction. A fifth factor is cloud cover, which can of course provide shade regardless of stream orientation.

The effect of stream orientation on water temperature has been noted by the Geological Survey at several streams. Two instances are described below.

1. In preparing thermograph records for the open-file compilation report, some of the gaps in the records were filled by correlation with nearby thermograph records. The monthly temperatures of Five Rivers near Fisher were correlated for this purpose with those of Fall Creek near Alsea. The relation curve was found to change seasonally, as shown by figure 4 . During the winter the two streams are about the same temperature, whereas during the spring and summer Five Rivers becomes progrossively warmer than Fall Creek. The two streams drain areas that are culturally and geologically similar, and neither receives significant spring-flow contributions. Investigation revealed that Fall Creek runs nearly north-south and has heavily wooded banks, whereas Five Rivers has a general east-west cours?. Furthermore, in those reaches of Five Rivers where the general direction is north-south, wide sweeping curves result in most of the stream having an east-west orientation. This fact led to the conclusion that the sun shining directly on the east-west strearn caused the water to be warmer than that in the north-south strean, where there was much less exposure to direct sunlight. As a further check on this conclusion, another north-south-oriented stream 
(Drift Creek near Salado) was selected for correlation with Fall Creek near Alsea. Excellent correlation, with no seasonal variation, was found between these two north-south streams. (See fig. 4.)

2. During the summer of 1963 the Geological Survey obtained watertemperature records on both North and South Forks of the Trask River. Maximum-minimum thermometers were ins ${ }^{\perp}$ alled and were read every 2 weeks; in addition, an observer messured the water temperature of both streams daily. These records do not appear in the compilation report (Moore, 96) because only records through September 30,1962, are included. At the time the records were begun, the observer pointed out that the North Fork was much warmer than South Fork and was used for swimming in preference to South Fork. The first records, in July, showed that North Fork was indeed $4^{\circ}-8^{\circ}$ F. warmer than South Fork. South Fork was tested with a hand thermometer for several miles upstream to determine if there were evidence of any springflow contributions that would account for the stream being colder than North Fork. None was found. Evidently the difference

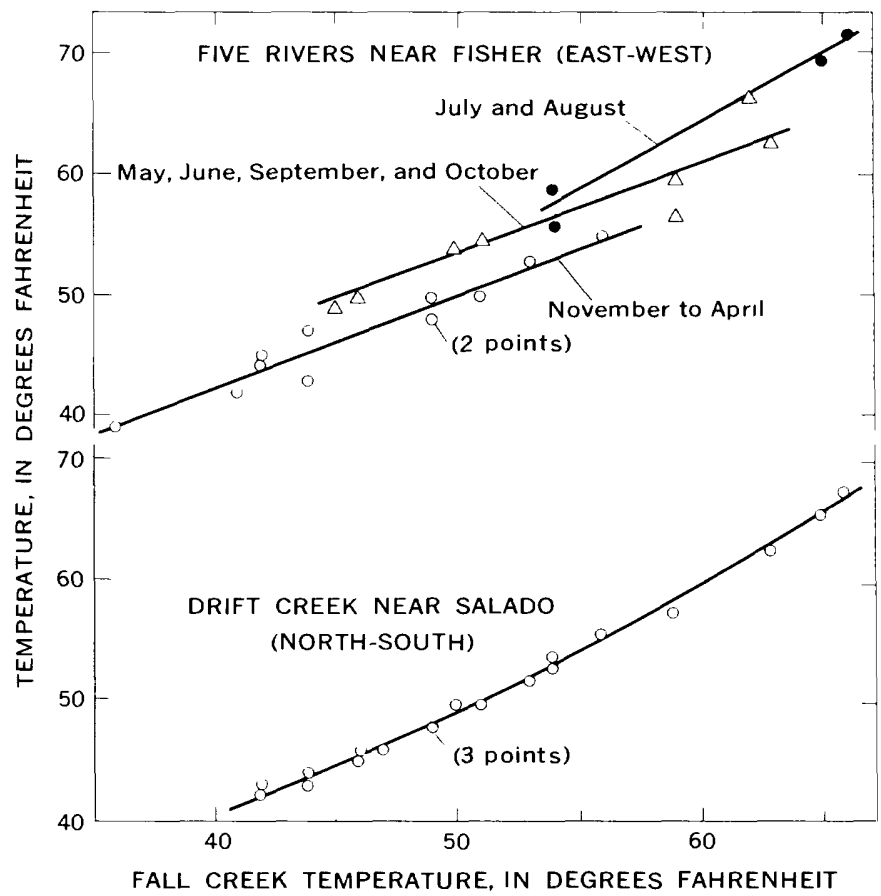

Figure 4.-Correlation of monthly extremes of water temperature of Fall Creek near Alsea (north-south orientation) with corresponding water temperatures of Five Rivers near Fis.her (east-west) and Drift Creek near Salado (north-south). 
was caused by the north-south orientation of South For]- Trask River and the east-west orientation of North Fork Trask: River. This conclusion was further supported when cloudy d'ays resulted in closer agreement between the temperatures of the two streams. In fact, when cloudy weather continued for two or three consecutive days, the temperatures of the two streams became virtually identical. Further, a comparison of monthly mean temperatures for the two sites showed that North Fork was $4^{\circ} \mathrm{F}$. warmer than South Fork in July, $5^{\circ} \mathrm{F}$. warmer in August, $3^{\circ} \mathrm{F}$. warmer in September, and only $2^{\circ} \mathrm{F}$. warmer in October.

\section{SNOWMELT CONTRIBUTIONS}

The effect of snowmelt contributions on the temperatures of streams tends to be seasonal and is particularly noticeable in streams that drain high elvations where snowmelt continues into the summer months. In the section "Accuracy of Records" it was noted that the temperature of Wallowa River water is within $1^{\circ}$ or $2^{\circ} \mathrm{F}$. of the temperature of Grande Ronde River water except during June through August when, because of snowmelt contributions, the Wallowa is $3^{\circ}-9^{\circ} \mathrm{F}$. cooler than the Grande Ronde.

\section{AMOUNT, LOCATION, AND TEMPERATURE OF TRIBUTARY SPRING FLOW}

Because spring-flow temperatures approximate the mean annual temperature of the region, spring-flow contributions are usually warmer than surface streamflow in the winter and cooler in the summer. For this reason, streams that are largely spring fed, such as many of those in the Deschutes, McKenzie, and North Santiam River basins, not only have little diurnal fluctuation in temperature but have as little as $10^{\circ} \mathrm{F}$. annual fluctuation. The temperatures of the springs do not fluctuate nearly as much but, as water from them moves downstream, the effects of solar radiation and air temperature increase.

Although most perennial streams derive their flow from ground water during long periods of no rainfall, a "spring-fed stræam" as designated in this report is a perennial stream that receives relatively large contributions from ground water at one or several points. In streams that are not spring fed, ground-water accretions are not concentrated. In almost all stream basins a substantial part of all precipitation enters the ground and appears as runoff at a later date. Where streams are spring fed, the proportion of precipitation that goes into temporary ground-water storage is larger than where the streams are not spring fed; as a result, streamflow is better sustained 
in spring-fed streams than in non-spring-fed streams. There are, of course, various degrees to which a stream may be spring fed.

The small diurnal and annual fluctuations in temperature of springfed streams, as compared with non-spring-fed streams, is caused by the even temperature of the spring flow throughout the year and by the relatively large amounts of flow during the summer months.

\section{DISCHARGE}

The effect of discharge on water temperature is related to the watersurface area exposed to solar radiation and to air. As discharge increases at a given cross section, most streams change proportionally more in depth and in velocity than in width. Hence, discharge increases more rapidly than water surface area, and, accordingly, for larger discharges, the changes in water temperature resulting from varying conditions of solar radiation and air temperature will be proportionally smaller.

\section{AIR TEMPERATURE}

Air temperature affects water temperature through the advection of heat from air to water or vice versa, but not to the degree that might seem to be indicated by the correlation between the two. The close correlation is caused largely by the fact that solar radiation affects both water and air temperature. As pointed out in the section "Review of Literature," Mangan (1946) found that the monthly mern air temperature is a reasonable index of the monthly mean temrerature of the surface water but that normally the monthly mean water temperatures of Pennsylvania streams, from May through November, will slightly exceed the monthly air temperature of the region. In Oregon, too, air temperature is a reasonable index of water temperature, but, because of other factors affecting water temperature, some Oregon streams are warmer and some are cooler than air temperature. Figures 5 and 6 compare monthly water temperatures for selected years at nine thermograph sites with corresponding air temperatures at nearby U.S. Weather Bureau stations. The same year could not be used for all thermograph records because there was no one year in which all these thermographs were in operation.

Monthly mean water temperatures are higher than monthly mean air temperatures during the summer months at four of the nine sites (fig. 5) but lower at the other five sites (fig. 6). The four streams whose summer temperatures are higher than air temperatures are oriented east-west throughout most of the basin. Therefore, during daylight hours the water and the air above the water are exposed to direct sunlight, whereas the air temperatures with which the water temperatures are compared are obtained in the shade. Breitenbush 


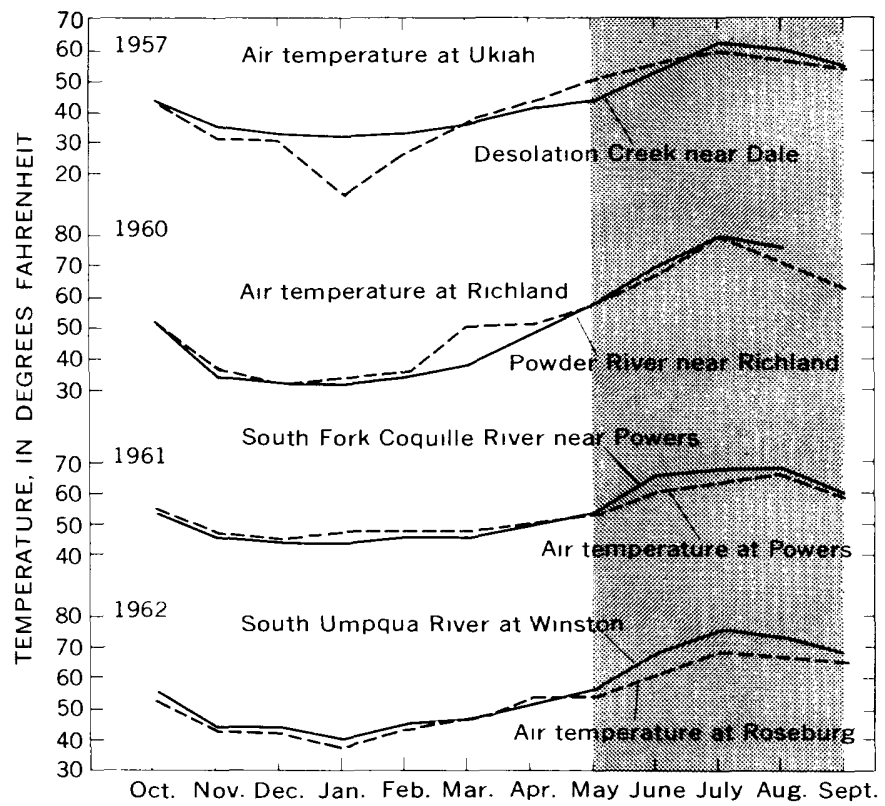

Figure 5.-Comparison of monthly mean air and water temperatures for selected east-west oriented streams. (Summer months shaded.)

River, although oriented east-west, is colder than the air during spring and summer months because of large spring-flow contributions Similar results are noted for North Umpqua River because of large amounts of spring flow and because of snowmelt contributions extending into the summer months. Spring flow does not contribute significantly to South Fork John Day, Clatskanie, and Grande Ronde Rivers, but they are colder than the air during the summer months. This is true largely because a north-south orientation and wooded banks minimize exposure to direct sunlight.

\section{MAN-CAUSED FACTORS}

Man influences stream temperature by polluting the streams with municipal and industrial wastes, using the water as a coolant, using the water for irrigation, and impounding the water in reservoirs.

Pollution can cause an increase in the temperature of streams in two ways. First, oxidation of the waste materials generates heat; and second, the temperature of the influent pollutants themselves may be higher than that of the stream. However, stream temperat xres in Oregon are probably less affected by pollution than by natural factors.

Industrial use of water as a coolant in Oregon has not yet caused serious problems similar to those that have arisen in highly industrial- 


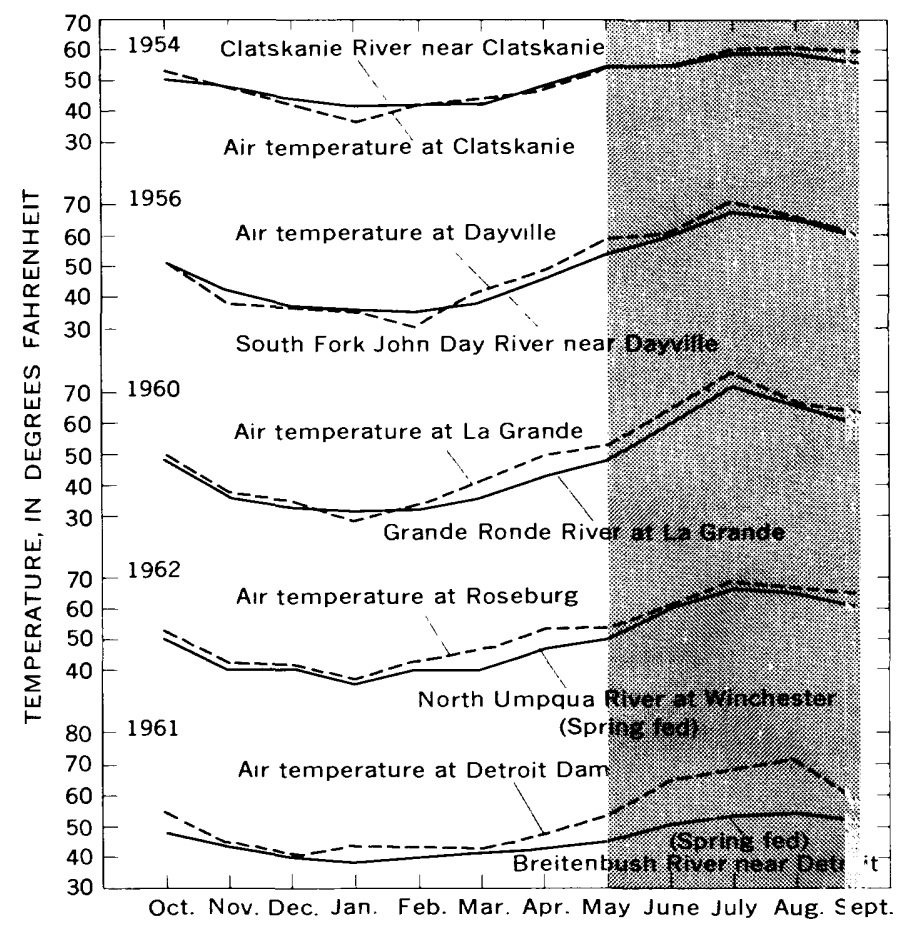

FIgure 6.-Comparison of monthly mean air and water temperatures for selected spring-fed or north-south oriented streams. (Summer months shaded.)

ized sections of the country. The atomic energy plant at Richland, Wash., for example, uses Columbia River water for cooling purposes and apparently has warmed the water to the extent that irteragency action was necessary some years ago to provide counteracting releases of cool water at Coulee Dam. But even in the Columbia River, natural factors affect stream temperature far more than does industrial use.

Return flows of water from irrigated land can raise or lower stream temperature. The direction and magnitude of the effect depend on the method of return, the amount of return flow as compared with flow in the stream, and the time of year when return flow raches the stream. Water returned in open drains during the summor months is warmer than water returned in closed drains. Water returned as ground water effluent may take months or years to reach the stream; that water which returns during the summer cools the stream, whereas that which returns during the winter warms the stream.

Impoundment of water in reservoirs generally changes the watertemperature regimen downstream. 
This report does not consider the effects of pollution and industrial use of water for cooling purposes because these factors do not significantly affect the temperature of Oregon streams. The effect of irrigation return flows is more significant but is not explored further because of a lack of data concerning this extremely complex factor. Impoundment of water in reservoirs is probably the most significant mancaused factor affecting stream temperatures in Oregon. Data are available concerning the effect of impoundments, but discussion of this factor is reserved for a later section of this report so that interstreamtemperature correlations, used in the appraisal of reservoir effects, can be discussed first.

\section{INTERSTREAM-TEMPERATURE CORRELATIONS}

The spot observations of water temperature obtained at more than 200 gaging stations in Oregon (see pl. 1) can be utilized directly to obtain means and extremes of water temperature on a monthly basis. Obviously, extremes for each month of each year and monthly mean water temperatures cannot be thus obtained because with only 8-10 observations a year, there is at most only 1 observation each month, and in some months there are none. Period-of-record means and extremes can be obtained from these observations for the 12 months of the year if observations are made over a period of many years. Admittedly, such figures are much less accurate than means and extremes obtained from a thermograph record. However, it is possible, through correlation, to estimate monthly figures that are far more accurate than those based on the spot observations alone.

This section of the report describes an unsuccessful attempt to correlate spot observations with air temperature and stream discharge, and the successful correlation of these observations with a thermograph record. However, before describing those methods of correlation, some of the terms used in this and following sections are explained to reduce the possibility of confusion or misunderstanding.

Observed mean.-Computed by averaging all observations of water temperature for a given month of the year. Thus, the observed mean for October is the average of observations made in all Octobers.

Observed maximum or minimum.-The highest or lowest water temperature observed in a given month. The observed maximum for October is the highest temperature ever observed in October.

Estimated temperatures.-Temperatures obtained for the spotobservation site by correlation with a thermograph record. In the open-file compilation report (Moore, 1964), and in a few places in this report, these temperatures are designated as "adjusted." 
Monthly mean.-The mean (average) water temperature for a specific month and year, such as October 1960.

Mean monthly.-The mean (average) of the water temperature for two or more of the same calendar months, such as the moan of all Octobers from 1954 to 1962.

Period-of-record means and extremes.-For a given site these consist of 12 mean monthly water temperatures, 12 maximums, and 12 minimums, corresponding to the 12 months of the year. For a given month, such as October, the maximum is the highest temperature and the minimum is the lowest temperature occurring during ar $y$ October within the period of record. If the record is obtained by correlation with a thermograph record, the period of record is that of the thermograph.

\section{ATTEMPT TO CORRELATE SPOT OBSERVATIONS OF WATER TEM- PERATURE WITH AIR TEMPERATURE AND STREAM DIS'THARGE}

An attempt was made to correlate observed water temperatures with the almost simultaneous observations of air temperatures made by the Geological Survey when visiting gaging stations. T'e plotted points scattered widely, largely because water temperature lags behind air temperature in responding to solar radiation. The scattering of points was greatly reduced when stream discharge was introduced as a second parameter, but standard errors for these multiple correlations were still as high as $5^{\circ} \mathrm{F}$. Furthermore, even if satisfactory relation curves were developed, monthly air temperatures at the gaging stations are not available and estimates of means and extremes of water temperature would depend on use of air-temperature records from a Weather Bureau station many miles away. Therefore, attempts to correlate spot observations of water temperature with simultaneous observations of air temperature were abandoned.

\section{CORRELATION OF SPOT OBSERVATIONS OF WATER TEMPERATURE WITH THERMOGRAPH RECORDS}

Correlation of spot observations of water temperature with thermograph records was tried at three sites and found to be satisfactory. The correlation process consisted of developing a curve of relation between spot observations at one site and temperature as re?orded on a thermograph at another site. Because the date and the time of day were documented for the spot observations, it was possible to obtain water temperatures at the thermograph site that corresponded exactly in time to those at the spot-observation site. This eliminated errors that might otherwise have resulted from failure to take into account diurnal fluctuation of water temperature. 
From these correlations it was possible to estimate monthly means and extremes corresponding to each month-of-record at the thermograph site. This was done for the three sites mentioned above. Thermograph records actually were arailable for those sites but were temporarily ignored, and the water temperatures observed at times of visits to those stations were treated as spot observations. At one site 54 months of record was estimated; at another, 62 months; and at the third site, 108 months. Comparison of the estimated records with the actual thermograph records for the respective sites showed that for all three correlations the standard error of estimate for the monthly means and extremes was only about $2^{\circ} \mathrm{F}$, and very few of the monthly estimates were more than $3^{\circ} \mathrm{F}$. in error.

These same correlation methods were used in the compilatior report, but the decision was made to obtain only period-of-record menns and extremes for each of the 12 months. Reasons for this decision were as follews:

1. Period-of-record figures will probably satisfy most needs.

2. The work involved in the compilation report would have been greatly increased if means and extremes were estimated for each month of every year.

3. Even though standard errors involved in estimates of temperatures for individual months were small, the standard errors for estimates of period-of-record means and extremes were even smaller. At all three of the sites tested, standard errors for estimates of period-of-record means were found to be less than $1^{\circ} \mathrm{F}$., and all such means were found to be correct within $2^{\circ} \mathrm{F}$. Titor the estimates of period-of-record monthly maximums and mirimums, the standard errors ranged from less than $1^{\circ} \mathrm{F}$. to slightly less than $2^{\circ} \mathrm{F}$.

These standard errors are far smaller than those for corrslations between spot observations of air temperature and water temporature. The thermograph record is affected by many of the same factors that affect the spot observations, and, thus, this one simple cor"elation integrates the influence of many factors affecting water temparature. For example, if discharge is far below average at the spot-observation site, a similar condition is likely to exist at the thermograph site used for correlation. If cloudy conditions exist in the spot-observation basin, they probably exist also in the basin from which the thermograph record is obtained.

Because the estimated temperatures for the spot-observation site represent those occurring during the period of record at the thermograph site, use of long-term thermograph records in the correlations was a leading consideration. 
One of three thermograph records was used for the corrolations at more than 200 spot-observation sites included in the compilation report. The three records were for Desolation Creek near Dale, Middle Santiam River at mouth near Foster, and Breitenbush River above Canyon Creek near Detroit, for periods of record covering 1951-58, 1954-62, and 1951-62, respectively. The use of thermographs with the same period of record would have been desirable; hcwever, all three of the records used are representative of long-term conditions, as shown in the section "Variability of Water Temperatur.." Desolation Creek was used for eastern Oregon correlations as it is the only thermograph record of any length in that area. Middle Santiam River was used because it is centrally located in western Oregon and appears to have a water-temperature regimen typical of many streams in western Oregon. Breitenbush River was used because it has a long period of record and substantial spring-flow contribution which correlate it well with other spring-fed streams. In choosing the thermograph record to use for each correlation, Desolation Creek was generally used for eastern Oregon streams and Middle Santiam River for western Oregon streams, except that Breitenbush River was generally used for those streams with large spring-flow contributions. Sometimes the period of record for the spot-observation site dictated the choice of thermograph record. For example, a western Oregon stream with spot observations from 1951-55 would probally be correlated with Breitenbush River, as Middle Santiam River thermograph record did not begin until 1954 .

As mentioned earlier, the estimated means and extremes for the spot-observation sites should generally be considered as tr ose applicable for the period of record of the thermograph used for correlation. There are exceptions to this, however, as sometimes the observed minimum is lower or the observed maximum is higher than the corresponding estimated temperature. This can occur because correlation does not necessarily yield exact results or, more rarely, because an observed minimum or maximum occurring outside the period of thermograph record is more extreme than its counterpart that occurred during the period of thermograph record. Regardless of the reason, the observed minimum or maximum is used also as the estimated figure, designated as "adjusted" in the compilation report, if it is more extreme than that obtained by correlation. Thus, the estimated figures generally are considered to be the probablo temperatures at the spot-observation site during the period of record for the thermograph used in the correlation, but a few figures shown as adjusted figures may actually represent temperatures occurring outside that period. 
Figure 7 shows examples of two types of correlations. One remains virtually the same from month to month, and the other changes frequently throughout the year. Symbols are used to represent the months so that monthly or seasonal variations in the correlation can be readily recognized. Most of the correlations changed frexuently throughout the year. If, for the variable correlation shown in figure 7 , one curve were used for the entire year, the standard error of estimate would be about $2.5^{\circ} \mathrm{F}$; ; however, by defining relations for the individual months, the accuracy of the estimate is greatly improved. Admittedly, a few wild points indicate that some estimates possibly could be off by more than $5^{\circ} \mathrm{F}$; ; but, in general, the estimates are probably good within about $1^{\circ}-2^{\circ} \mathrm{F}$. (See section "Test of Effectiveness of Correlation Procedures.")

Some spot-observation records correlated so poorly with all three of the thermograph records that adjusted figures are not shown. This lack of correlation was particularly true of spot-observation re?ords in the Klamath River basin.

For several reasons, no attempt was made to correlate spot-observation data furnished by other agencies. First, most of these records did not show time of observation, which, as noted earlier, is ganerally needed for correlations because of diurnal fluctuation of water temperature. At some sites, two or three observations were made each day with the result that means and extremes for each month of each year, based on observations alone, were accurate, and improvement by correlation would be negligible. Records in this category were treated in the same way as thermograph records, with figures shown for each month of each year. For some furnished records, once-daily observations were considered to be accurate enough in themselves without correlation because they were made in streams where there was little diurnal fluctuation. These records, too, were treated in the same way as thermograph records. Temperature records for Willamette River as obtained by the State Sanitary Authority consist of two or more observations made for each summer month for several years. These records are not complete enough to treat as thermograph records, but the frequency of observations and the small diurnal fluctuation of Willamette River temperature are such that the observed means and extremes shown for the period of record for each month are re ${ }^{l}$ atively accurate estimates of true means and extremes, and correlation would result in little, if any, improvement. In other words, these Willamette River records were treated as spot-observation records showing only the period-of-record means and extremes as computed from the observations alone. 

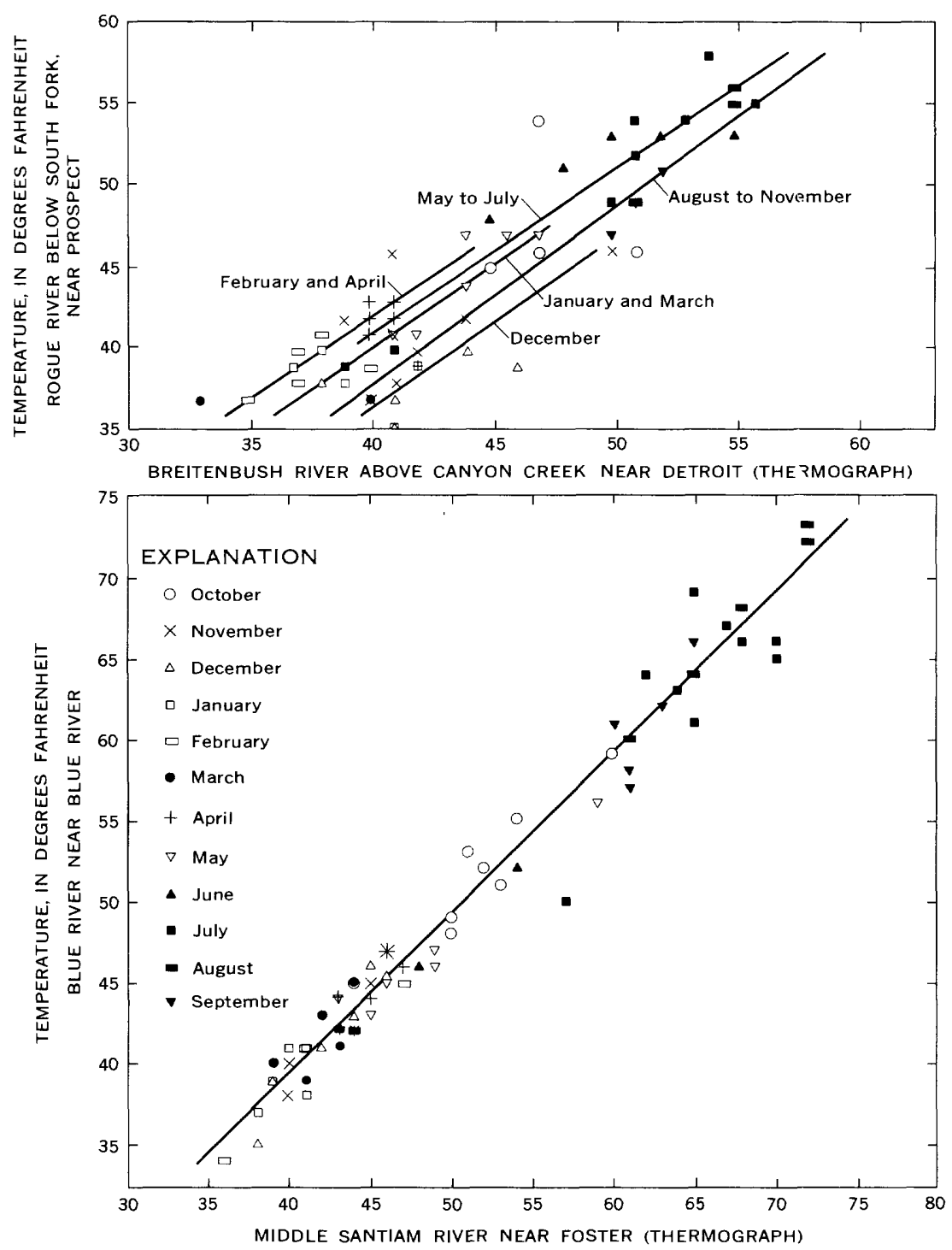

FIgURE 7.-Typical water-temperature correlations showing a seasonal variation and a constant relation between spot observations and a thermography record.

TEST OF EFFeCTIVENESS OF CORRFLATION PROCEIURES

Procedures were described earlier by which thermograph records at three sites were temporarily ignored and spot-observation data at those sites were correlated with a thermograph record on another stream to determine how closely the true thermograph records could 
be reproduced. That was a test to find out if such methods of correlation were applicable, but it also provided some information as to the effectiveness of the procedures. However, a more exhaustive check of effectiveness was considered to be desirable. Tests similar to those described earlier for 3 sites were made for 26 thermograph sites, but in these tests the use of correlation was limited to estimating the periodof-record means and extremes for each month. Table 2, which lists the results of these tests, would be unwieldy if period-of-record monthly temperatures corresponding to those computed from obse"vations (observed), those estimated by correlation (adjusted), and those obtained from the true thermograph records were shown. Instead the difference between observed and true figures and between adjusted and true figures are shown, and those differences, designated as errors, are cumulated without regard to sign for the 12 months of the year. On page K31, detailed sample computations are listed to show how cumulative errors were computed.

Almost all thermograph stations with at least 4 years of record were used for this test. Shorter records do not constitute a good test, and sufficient longer records were available to provide conclusive evidence as to the effectiveness of correlation procedures.

As previously explained, when spot observations are correlated with a thermograph record, the adjusted figures that are obtained are basically equivalent to the probable means and extremes occurring at the spot-observation site, but for the period of record of the thermograph used for the correlation. In testing these correlation procedures, however, adjusted figures must be obtained which correspond to the period of thermograph record at the test site. For example, the thermograph record for Bull Run River at Bull Run is for th a period August 1950-September 1954. To see how well the spot observations for basically this same period can be correlated with the thermograph record for Breitenbush River above Canyon Creek near Det:oit, it is necessary to enter the correlation curve using means and extremes for Breitenbush River which also are for the period August 1950-September 1954 .

Observed means more closely approximate the true means than do observed extremes approximate the true extremes. The renson for this is that, for any given month, some observed temperatures are above the mean and some are below; therefore, departures from mean tend to cancel each other. No such cancellation is possible for the extremes, which consist of the highest and lowest observations throughout all the years of record for a given month. Even when cancellation of departures was taken into account, the observed means were in surprisingly good agreement with actual thermograph means; differences generally averaged less than $2^{\circ} \mathrm{F}$. per month. It follows 
TABLE 2.-Comparison of errors in observed and adjusted water terperatures to show effectiveness of correlation procedures

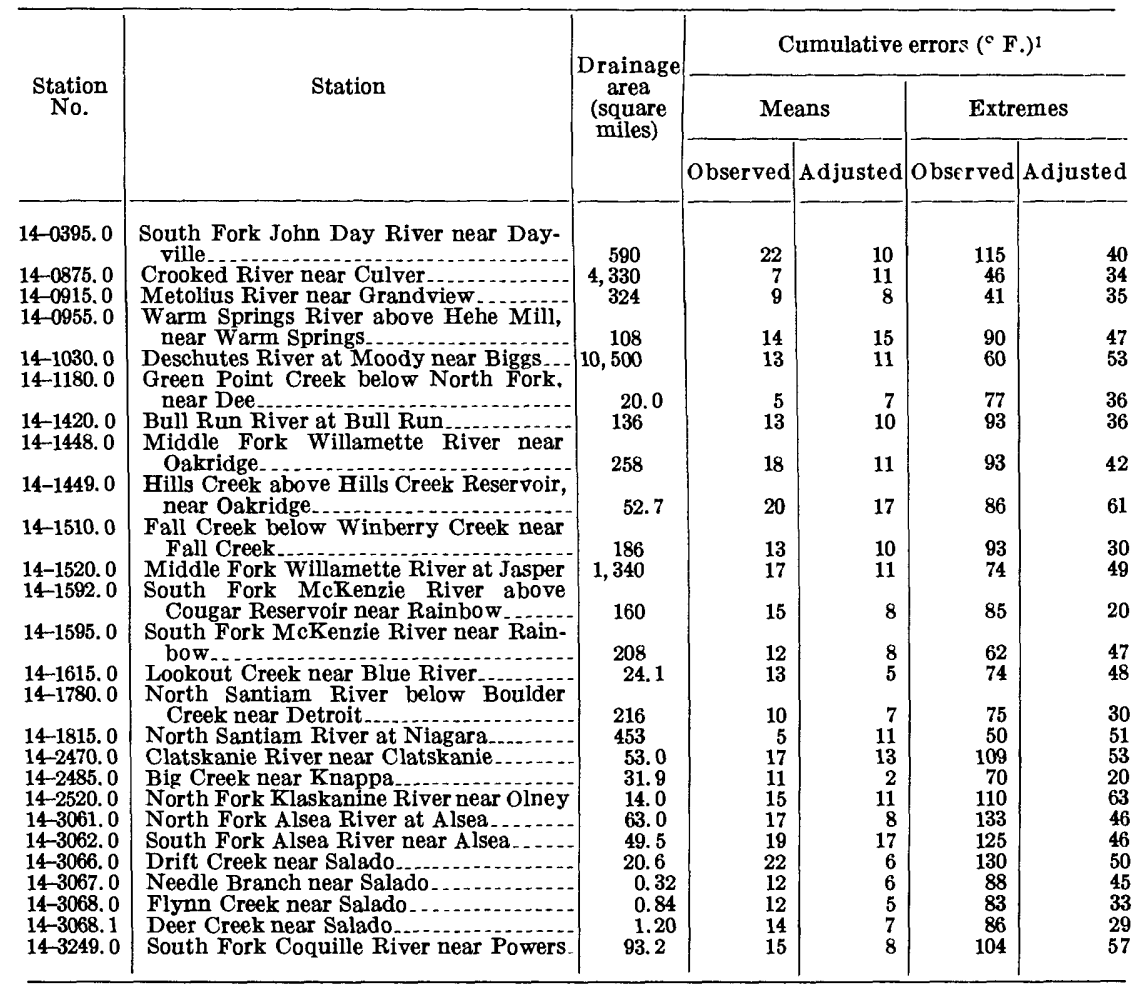

1 Cumulative errors represent the difference between both the observed and adjusted figures and the true thermograph record, cumulated without regard to sign for the 12 months of the year. F r example, for South Fork John Day River the cumulative errors of $22^{\circ} \mathrm{F}$. for the observed means and $115^{\circ} \mathrm{F}$. for the observed extremes show that the 12 monthly observed means differed from the thermograph means by an average of about $2^{\circ} \mathrm{F}$., whereas the 24 observed extremes differed from thermograph extremes by an average of almost $5^{\circ} \mathrm{F}$. Correlation of the spot observations with a nearby thermograph record resulted in adjusted means that differed from true thermograph record by an average of less than $1^{\circ} \mathrm{F}$. and ad'usted extremes that differed by an average of about $1.5^{\circ} \mathrm{F}$.

then that the adjusted means cannot show much improvement over the observed means because the standard error of correlation was generally on the order of $1^{\circ}-1.5^{\circ} \mathrm{F}$.

The cumulative error (difference from thermograph record for same site) of the observed monthly extremes for the 26 stations listed in table 2 averaged $87^{\circ} \mathrm{F}$. for the year; this amounts to an average error of $3.6^{\circ} \mathrm{F}$. for each of the 12 monthly maximums and minimums involved. With certain exceptions, correlation procedures generally cut these errors by 50 percent or more. The second througl the fifth sites listed in table 2 are on spring-fed streams at places where there is little variation in water temperature throughout the year, and both observed means and extremes are accurate enough that little or no improvement through correlation is possible. However, for one of these sites, Warm Springs River near Warm Springs, the cumulative 


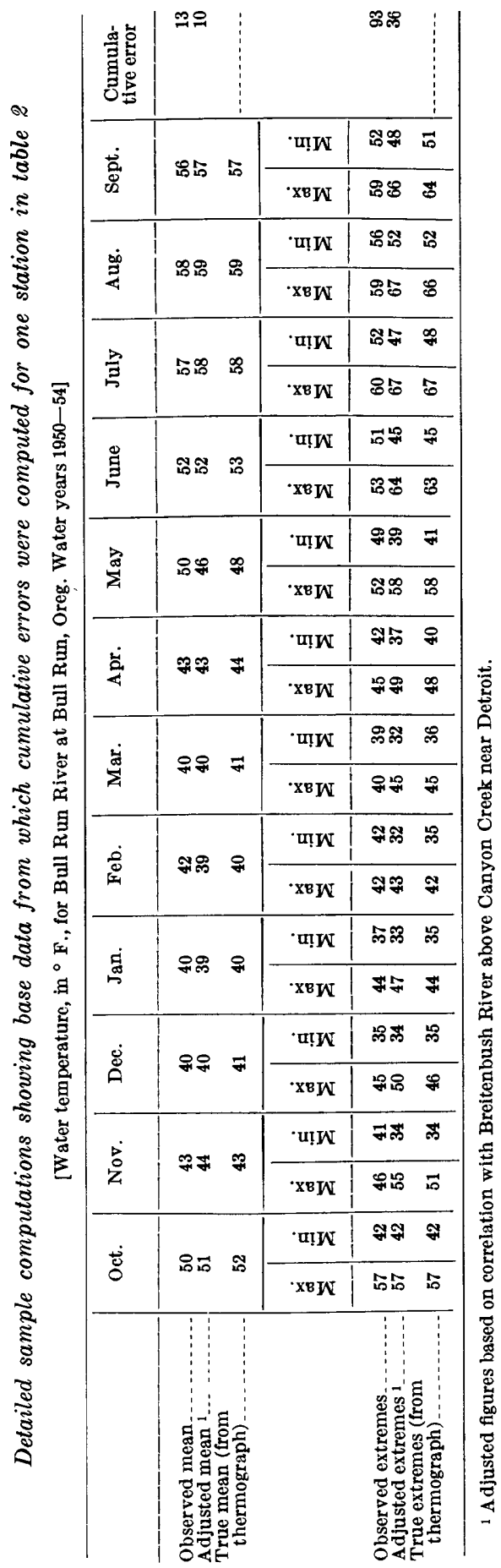


error in monthly extremes is $90^{\circ} \mathrm{F}$. for observed figures and cnly $47^{\circ} \mathrm{F}$. for adjusted figures. The improvement shown here is due partly to the fact that the period of record is only $4 \frac{1}{3}$ years (too fer observations to yield accurate "observed" monthly figures), and partly to the fact that the stream is not as markedly spring fed as are the others.

North Santiam River at Niagara was included as a test site to determine if any correlation with a thermograph record would be found where the flow was completely regulated by Detroit Reservoir. Some correlation was found, but the relationship changed seasonally, so that about five different curves were required for the year. Reservoir releases of relatively cool water in summer and relatively warm water in winter result in conditions similar to those in spring-fed streams. Observed means were very close to actual means, with exact agreement for 7 months and errors of $1^{\circ} \mathrm{F}$. in each of the other 5 months. The observed monthly extremes were also reasonably accurate, and no improvement through correlation was possible.

For 21 test sites, excluding the four spring-fed streame and the one regulated stream, the average error of the observed neans was $1.8^{\circ} \mathrm{F}$. per month, and that for the adjusted means was $0.7^{\circ} \mathrm{F}$. per month. Similarly, the average error of observed maximums and minimums was $3.9^{\circ} \mathrm{F}$.; it was reduced through correlation to $1.7^{\circ} \mathrm{F}$.

General conclusions are as follows:

1. For streams that are not largely spring fed, correlation procedures definitely reduce the errors inherent in the use of temperatures based only on spot observations. Although the improvement in monthly means is only about $1^{\circ} \mathrm{F}$. because the observed figures are comparatively accurate, the percentage of improvement is about as great as it is for monthly extremes, for which average errors of $4^{\circ} \mathrm{F}$. are reduced to less than $2^{\circ} \mathrm{F}$.

2. For spring-fed streams, water temperature varies so littlo that observed means are more accurate than the correlations that would be used to adjust these figures. Correlation procedures do result in some improvement in the accuracy of the monthly extremes, particularly where the spot-observation record covers a period of only a few years.

\section{EFFECT OF RESERVOIRS ON DOWNSTREAM WATER TEMPERATURE}

Reference was made earlier ( $\mathrm{p} . \mathrm{K} 6$ ) to statements by Sylvester $(1963$, p. 15,17$)$ concerning nine items which determine the effect of a reservoir on the temperatures of impounded and downstream waters. The four major factors with respect to downstream temperature are the volume of water impounded, depth of impounded water, depth at 
which water is withdrawn, and rate of withdrawal as compared with rate of natural flow.

The effect of Oregon reservoirs on downstream water temperatures was studied. For some reservoirs the effect was determined using water-temperature records of inflow and outflow. For other Oregon reservoirs, the effect was determined from "before" and "after" watertemperature records (records downstream from a reservoir site, obtained before and after the reservoir was constructed). At some sites, and for both types of studies, only spot-observation records were available. For most reliable results, the records should be from a thermograph operated at the same site for several years before and after the construction of the reservoir. The thermograph would ensure accurate temperatures, and long records would help to make certain that apparent changes in the water-temperature regimen are not wholly or partly the result of meteorological differences between the two periods. Such an ideal situation with respect to records is seldom found. Frequently there are no thermograph records for the periods before or after construction of the reservoir, or there is only a short record. To analyze the effect of a reservoir, therefore, it often is necessary to use short thermograph records, which may include some natural variations in water temperature, or spot-observation records.

\section{INFLOW AND OUTFLOW RECORDS}

When inflow and outflow temperature records are utilized in these studies, the risk of comparing two periods for which meteorological conditions differed markedly is eliminated. However, there is usually no way to measure the change that would have occurred between the inflow and outflow sites under natural conditions (without the reservoir) unless, of course, these records were obtained both before and after construction of the reservoir. The open-file compilation of water temperature data includes instances where two or more records were collected at different sites on the same unregulated stream. These show that natural temperature gradients are usually upward in a downstream direction, but that they may be downward during the winter months. During the summer period of critical temperatures, the gradient may be as much as $1^{\circ} \mathrm{F}$. per mile, depending on such things as the shade provided, the amount of flow, and the stream temperature. In Oregon, however, the gradient usually is much less than $1^{\circ} \mathrm{F}$. per mile, and a reasonable summertime average appears to be $0.2^{\circ} \mathrm{F}$. per mile. Because of the natural temperature gradient in the stream, the cooling effect of a reservoir in summer is greater than that indicated by the difference between the inflow and outflow temperatures. For example, if the sites for inflow and outflow records for a given reservoir are 10 
miles apart and the records indicate mean temperatures of $66^{\circ}$ and $60^{\circ}$ $\mathrm{F}$., respectively, for the month of July, the apparent cooling is $6^{\circ} \mathrm{F}$. The actual cooling is probably about $8^{\circ} \mathrm{F}$. because without the reservoir the natural warming in that distance would probably have been on the order of $2^{\circ} \mathrm{F}$.

\section{“BEFORE" AND "AFTER" RECORDS}

"Before" and "after" thermograph records are available for some reservoirs such as Brownlee Reservoir on the Snake River, where thermographs were located just below Brownlee Dam, at $\mathrm{O}$-bow, and near Clarkston. Therefore, the effect of the reservoir on vater temperatures as far downstream as Clarkston, Wash. (about 145 miles), can be computed at each thermograph site by subtracting mean monthly water temperatures for the period before the reservoir was completed from those for the period after the reservoir was completed.

Thermograph records are not available for the inflow and outflow temperatures of some reservoirs, but there are spot-observation records which can be correlated with a thermograph record on an unregulated stream. If a spot-observation record below a reservoir includes periods before and after construction of the reservoir, it can be utilized to obtain "before" and "after" records, both of which represent the period of record for the thermograph record used for correlation. This can best be explained by the following example.

Detroit Reservoir, on the North Santiam River, was first used for storage in 1953, and complete inflow and outflow thermograph records have been kept. However, at Mehama (North Santiam River), about 22 miles downstream, and at Jefferson (Santiam River), about 51 miles downstream, only spot-observation records have been kept, but these date from 1947 to 1962 . The same correlation procedures were followed at Mehama and Jefferson, but only Mehama is discussed here. The Breitenbush River thermograph record, one of the inflow thermograph records for Detroit Reservoir, covers the period 1951-62. Separate correlations with the Breitenbush thermograph record were made for spot observations of water temperature at Mehama before and after the filling of Detroit Reservoir. That is, the 1951-52 spot observations were correlated with the 1951-52 thermograph record for Breitenbush River. By entering this correlation with the known period-of-record (1951-62) mean monthly temperatures for the Breitenbush River, the corresponding mean monthly temperatures at Mehama for the same period (1951-62) were determined. These are the mean monthly temperatures that would have occurred at Mehama if Detroit Reservoir had never been created. A similar correlation for the period 1953-62, when entered with the same 1951-62 mean 
monthly temperatures for the Breitenbush River, yielded the mean monthly temperatures that would have existed at Mehama for 1951-62 if Detroit Reservoir had been in operation for the entire period. Therefore, the 2- and 10-year correlations both resulted in estimates of mean monthly temperature at Mehama for the 12-year pericd 195162 , but the first excluded and the second included the effect of Detroit Reservoir. Subtraction of the "before" record from the "after" record gives the effect of Detroit Reservoir at Mehama. For simplicity and clarity, table 3 does not show water temperatures; only the effects of the reservoirs are shown.

The release of reservoir water having relatively constant temperature would likely result in poor correlation between spot observations of water temperature immediately below the reservoir and a thermograph record on an unregulated stream. However, as was pointed out earlier, observed mean monthly temperatures for spring-fed streams or streams immediately below a reservoir (whose characteristics are similar to those of spring-fed streams) are so accurate that they cannot be improved upon by correlation. Further, if the spot observations are made at a site several miles below the reservoir, good correlation with a thermograph record is usually found, because in those few miles the water is subjected to the same natural conditions that affect water temperature at the thermograph site. The correlations between the thermograph record for Breitenbush River and spot observations at both Mehama and Jefferson are reasonably good.

In general, the analyses of the effect of reservoirs on downstream water temperature, as shown in table 3, do not allow for the natural temperature gradients that existed between inflow and outflow sites before construction of the reservoirs because these gradients are not accurately known. In all instances, however, the distance between inflow and outflow sites is given so that the reader can roughly appraise the accuracy of the computed effects.

The natural temperature gradient is known, however, for 15 of the 19 miles separating the points where inflow and outflow records were obtained at Lookout Point Reservoir and for the approximately 10 miles between the inflow stations for Detroit Reservoir and the dam, and these two items are discussed next.

Thermograph records for October 1950-October 1953 (before completion of Lookout Point Reservoir) are available for Middle Fork Willamette River below North Fork near Oakridge and for Middle Fork Willamette River at Lowell. These records show that in the intervening 15 miles the average warming effect was $1^{\circ} \mathrm{F}$. for OctoberFebruary, $2^{\circ} \mathrm{F}$. for March-June, and $3^{\circ} \mathrm{F}$. for July-September. In table 3, the first line for Lookout Point Reservoir shows the effect of 


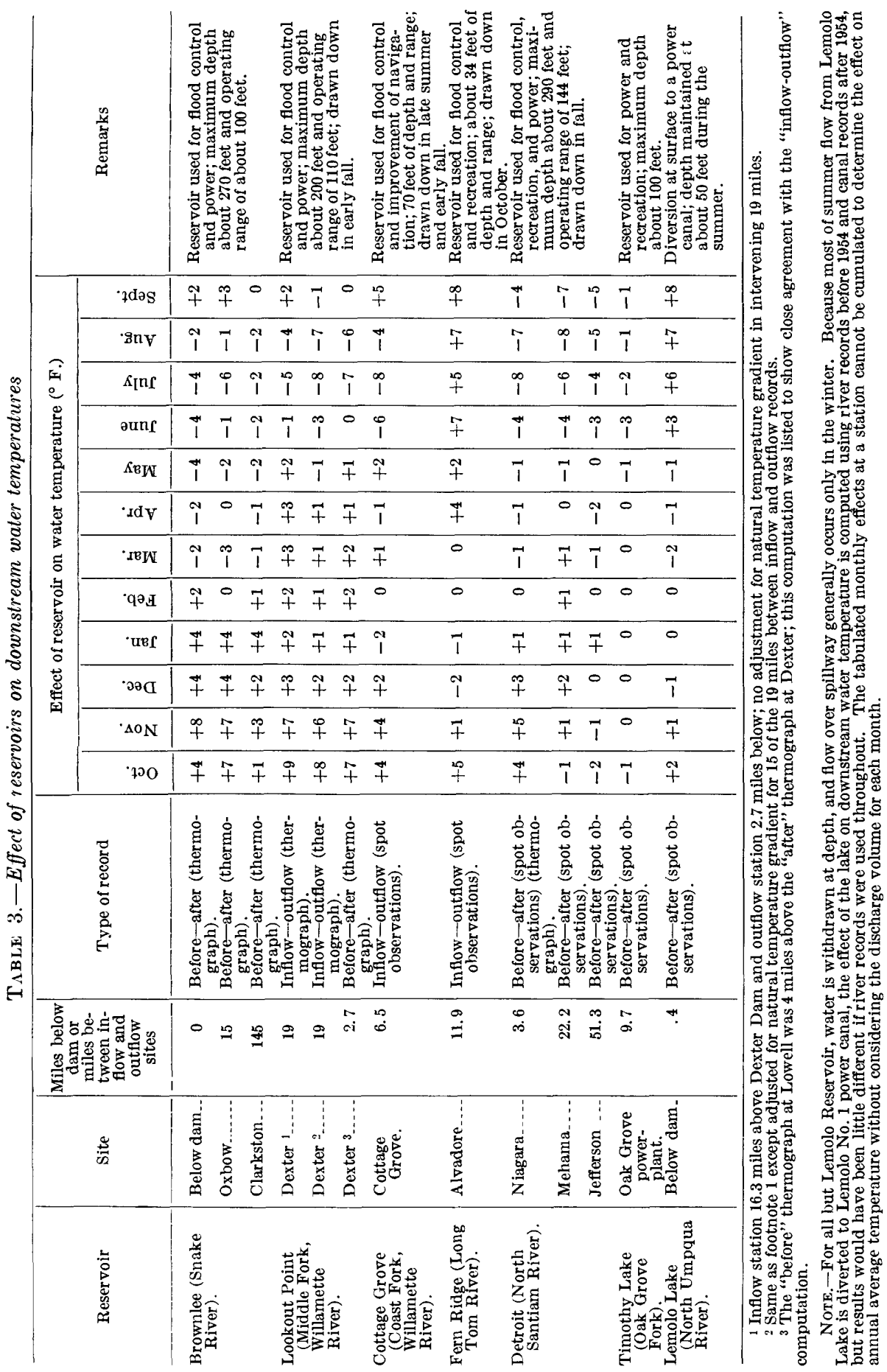


the reservoir on downstream temperatures, as computed from the inflow record (below North Fork) and the outflow record (at Dexter), with no allowance for temperature gradient in those 19 miles; the second line shows the same effect but with corrections applied for temperature gradient of $1^{\circ}-3^{\circ} \mathrm{F}$. (as listed above). Because the Lowell station was 4 miles upstream from Dexter, the temperature gradient for the 4 miles has still not been taken into account but should be less than $1^{\circ} \mathrm{F}$. even in the summer months. Note how closely the second line, in which temperature gradient is largely taken into account, corresponds to the third line, which shows computed effect kased on "before" and "after" thermograph records. Because the "before" record was at Lowell and the "after" record was at Dexter, the third line, as well as the second, does not reflect the natural temperature gradient between Lowell and Dexter.

Mean monthly temperatures for the period 1951-62 are estimated from the spot-observation record for North Santiam River above Mayflower Creek (at the damsite prior to completion of Detroit Reservoir in 1953) by correlation with the record for Breitenbush River. When these are compared with the mean monthly temperatures for the same period at the two inflow stations, both of which are almost 10 miles upstream from the dam, the natural temperature gradient in this 10 mile reach is found to be about $+2^{\circ} \mathrm{F}$. for October, $+1^{\circ} \mathrm{F}$. for November-April, $+2^{\circ} \mathrm{F}$. for May, and about $+3^{\circ} \mathrm{F}$. for June-September. In computing the effect of Detroit Reservoir on water temperatures at Niagara, 3.6 miles below the dam, the spot-observation record "above Mayflower Creek" is used as the "before" record and the Niagara thermograph record is used as the "after" record, rather than using inflow and outflow thermograph records for stations that are about 13 miles apart. In so doing, only the natural temperature gradient in the 3.6 miles of stream between Detroit Dam and the Niagara thermograph is ignored.

The following conclusions can be drawn from the data shown in table 3 :

1. When water is withdrawn from a deep reservoir at a level that is well below the surface, downstream temperatures are generally lowered during the summer months, raised during the autumn months, and unchanged during the winter and spring months.

2. For shallow reservoirs such as Fern Ridge Reservoir and Lemolo Lake, downstream temperatures are generally raised from late spring to early fall and unchanged at other times.

3. As shown by data for Brownlee and Detroit Reservoirs, the effect of a reservoir can extend for many miles downstream. 
4. There appears to be a time lag in the cooling effect of Detroit Reservoir as releases pass downstream; that is, the maximum temperature change at Mehama appears to occur about 1 month later than at Niagara, and that at Jefferson, about 1 month later tl an that at Mehama.

Some of these conclusions warrant further discussion. With respect to item 2 above, the waters of the North Umpqua River are so cool that the warming by Lemolo Lake would probably have been much less were it not for the fact that water is withdrawn from the surface of the lake. Similarly, the waters of Oak Grove Fork in the upper Clackamas River basin are naturally so cool that releases from Timothy Lake can result in only little cooling during the summor months.

The effect noted in item 4 above is believed to be due to the changed water-temperature gradient between Niagara and the downstream sites, and to the change in flow pattern. Both changes are the result of reservoir regulation. For example, the natural temperature difference between Niagara and Mehama for July is $+5^{\circ} \mathrm{F}$. $\left(56^{\circ}-61^{\circ}\right.$ $\mathrm{F}$.), but with Detroit Reservoir in operation the difference is $+7^{\circ} \mathrm{F}$. $\left(48^{\circ}-55^{\circ} \mathrm{F}\right.$. $)$. The regulated $\mathrm{July}$ flow is about the same as the natural flow, but because water temperature at Niagara is $8^{\circ} \mathrm{F}$. cooler than under natural conditions evaporation is reduced and, therofore, less heat is dissipated by evaporation and more heat is available for warming the water. This same effect occurs in August and September also, but then it is more than offset owing to the fact that regulated flows are well in excess of natural flows. As there is more water to be warmed, the natural gradients between Niagara and Mehama of $+5^{\circ}$ $\mathrm{F}$. for August and $+4^{\circ} \mathrm{F}$. for September are cut to $+4^{\circ} \mathrm{F}$. and $+1^{\circ}$ F., respectively.

\section{VARIABILITY OF WATER TEMPERATURE}

The temperatures of Oregon streams vary widely from month to month and from year to year. During the summer months, most streams have considerable diurnal fluctuation in temperature.

The purpose of this section of the report is to develop rough guides by which to appraise this variability of water temperature. The three guides developed are:

1. A numerical scale that is of assistance in appraising monthly mean temperatures for July and August from short thermorraph records to determine whether these means represent avere.ge, cooler, or warmer conditions.

2. A table showing the probable recurrence intervals for period-ofrecord maximums and minimums for each month of tla year for Middle Santiam River at mouth near Foster and for Desolation 
Creek near Dale. Because these records were used for correlation with spot-observation records, the probable recurrence intervals apply within rough limits to period-of-record adjusted maximums and minimums at the spot-observation sites.

3. A table listing (a) all sites where the Geological Survey or other agencies have obtained thermograph records, and (b) the maximum diurnal fluctuation of water temperature registered at those sites. This table provides a rough guide as to diurnal fluctuation to be expected at any site.

\section{NUMERICAL SCALE FOR APPRAISING SHORT-TERM THERMOGRAPH RECORDS}

A yardstick for determining the significance of short-term thermograph records necessitates consideration of variables that are directly or indirectly related to water temperature.

A previous section of this report lists the major natural factors affecting stream temperature as solar radiation, shade, snowmelt contributions, tributary spring flow, discharge, and air temperature. Of these, a year-to-year variation in snowmelt or spring flow during July and August will be small. Radiation balance, air temperature, and discharge are the major variable factors contributing to the observed variations. As noted previously, there is correlation between air temperature and water temperature, because air temperature affects water temperature and, more importantly, because both are affected by solar radiation. Although correlation between spot observations of water temperature and simultaneous observations of air temperature is, as previously described, not good, there is excellent correlation between monthly means and extremes of water temperature and corresponding air temperature. Air temperature and discharge were, therefore, selected as the building blocks from which the rough scale or yardstick would be constructed.

Five U.S. Weather Bureau air-temperature records were selected on the basis of length of record, geographical coverage of the State, and ready availability of summary tables from which departures from long-term averages could be computed. For the five records, the departures from long-term averages were computed for July and August of each year and were plotted as bar graphs. The reason for computing departures for only July and August is that in almost every year the maximum water temperatures occur in one of those 2 months, and there is far greater interest in high temperatures than in low or average temperatures. High temperatures act as a deterrent to fish runs, intensify pollution problems, and make streams less suitable for industrial and recreational uses. 
The five U.S. Weather Bureau records for which bar graphs of departures from average air temperature were plotted are for Portland, Medford, Burns, Bend, and Pendleton. On the same graphs, the flows for July and August of each year were plotted for Sandy River near Marmot, Rogue River at Raygold, Silvies Piver near Burns, Lake Creek near Sisters, and South Fork Walla Walla River near Milton, respectively. Figure 8 shows the plot for the Bend weather record in relation to streamflow in Lake Creek near Sisters.

From the bar graphs for the various sites, water temperstures were deduced for July and August of each year as class 1, 2, 3, 4, 5, or 6class 1 representing the cool end of the scale and class 6 the warm end. Water temperature was considered to be class 1 when air-temperature departure from long-term average was $-4^{\circ} \mathrm{F}$. or more, class 2 for $-2^{\circ}$ to $-4^{\circ} \mathrm{F}$., class 3 for $-2^{\circ}$ to $0^{\circ} \mathrm{F}$, class 4 for $0^{\circ}$ to $+2^{\circ} \mathrm{F}$, class 5 for $+2^{\circ}$ to $+4^{\circ} \mathrm{F}$, and class 6 for above $+4^{\circ} \mathrm{F}$. These designations were then refined slightly on the basis of discharge. For example, if air-temperature departure was $+2^{\circ} \mathrm{F}$. or slightly more, the water temperature was deduced as class 5 if streamflow was below average to slightly above average, but was shaded to class 4 if streamflow was appreciably above average.

The classifications for all five sites are shown in table 4, which provides a rough guide to July and August water temperatures from 1913 to 1962 . There is remarkably good agreement thro'ighout the State for unusually cold or hot Julys and Augusts. From inspection of table 4, the following conclusions appear to be reasonable:

1. July 1916 and July 1955 are the only months that fall in class 1 ; therefore, the recurrence interval of the mean water temperature for July 1955 can be considered to be twice in 50 years or once in 25 years.

2. August 1958 and August 1961 are the only months that fall in class 6 ; therefore, the recurrence interval of the mean water temperature for those months can be considered to be once in 25 years.

3. Thermograph records that include the years 1955 and 1958 are (for July and August) representative of extremes for a 25-year period.

\section{TEST OF NUMERICAL CLASSIFICATION SCALE}

No attempt was made to check all thermograph records against the rough scales in table 4; however, to gain some insight ir to the applicability of these scales, a few checks were made, and the results are shown graphically in figure 9. The record for Fall Creek below Winberry Creek near Fall Creek was chosen because it covers the period 1950-62, which appears to be representative of the long-term average, and also because the creek is typical of many western Oregon streams. 


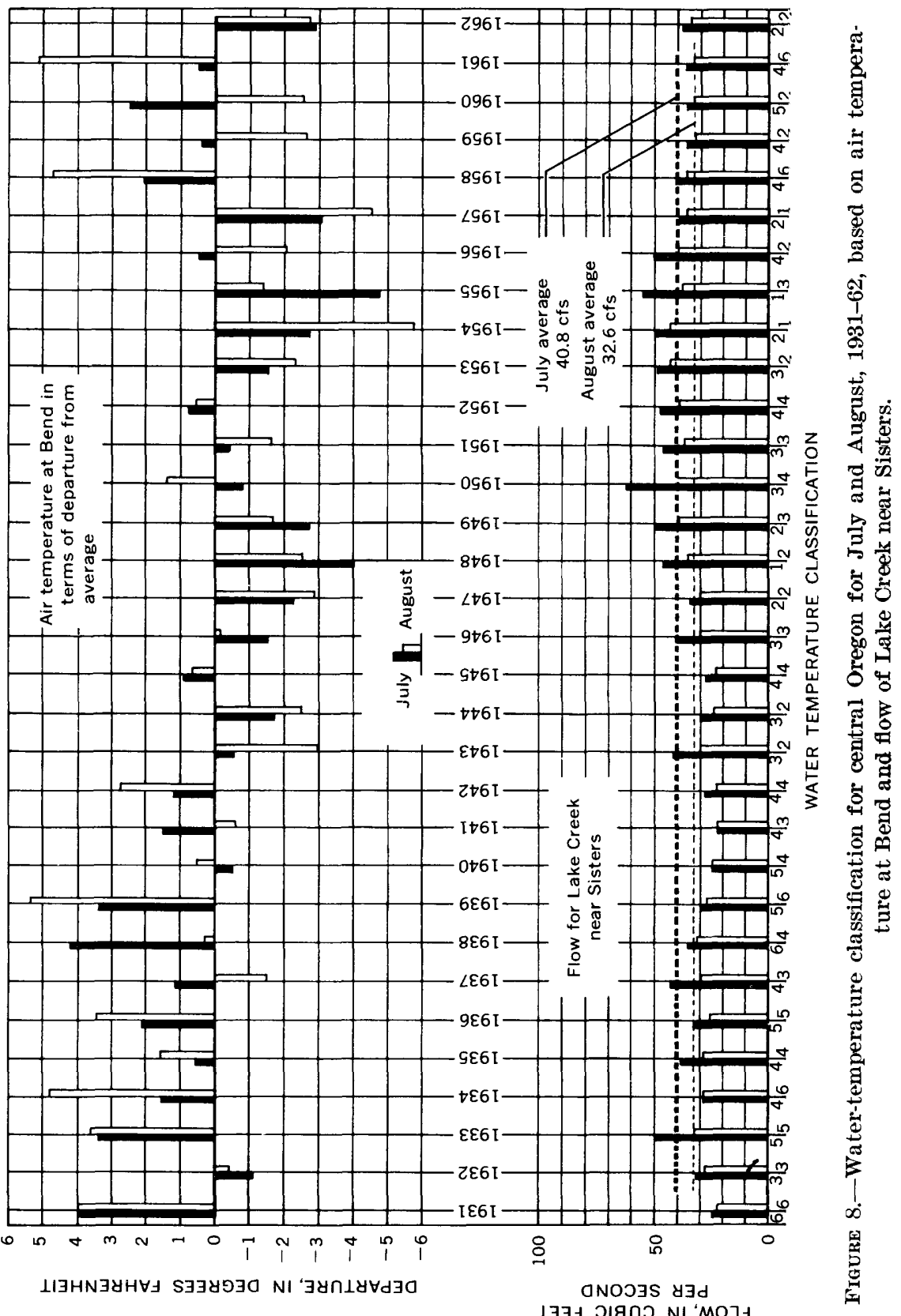


TABLE 4.-Numerical classification of water temperature

[In various sections of the State for July and August of years shown]

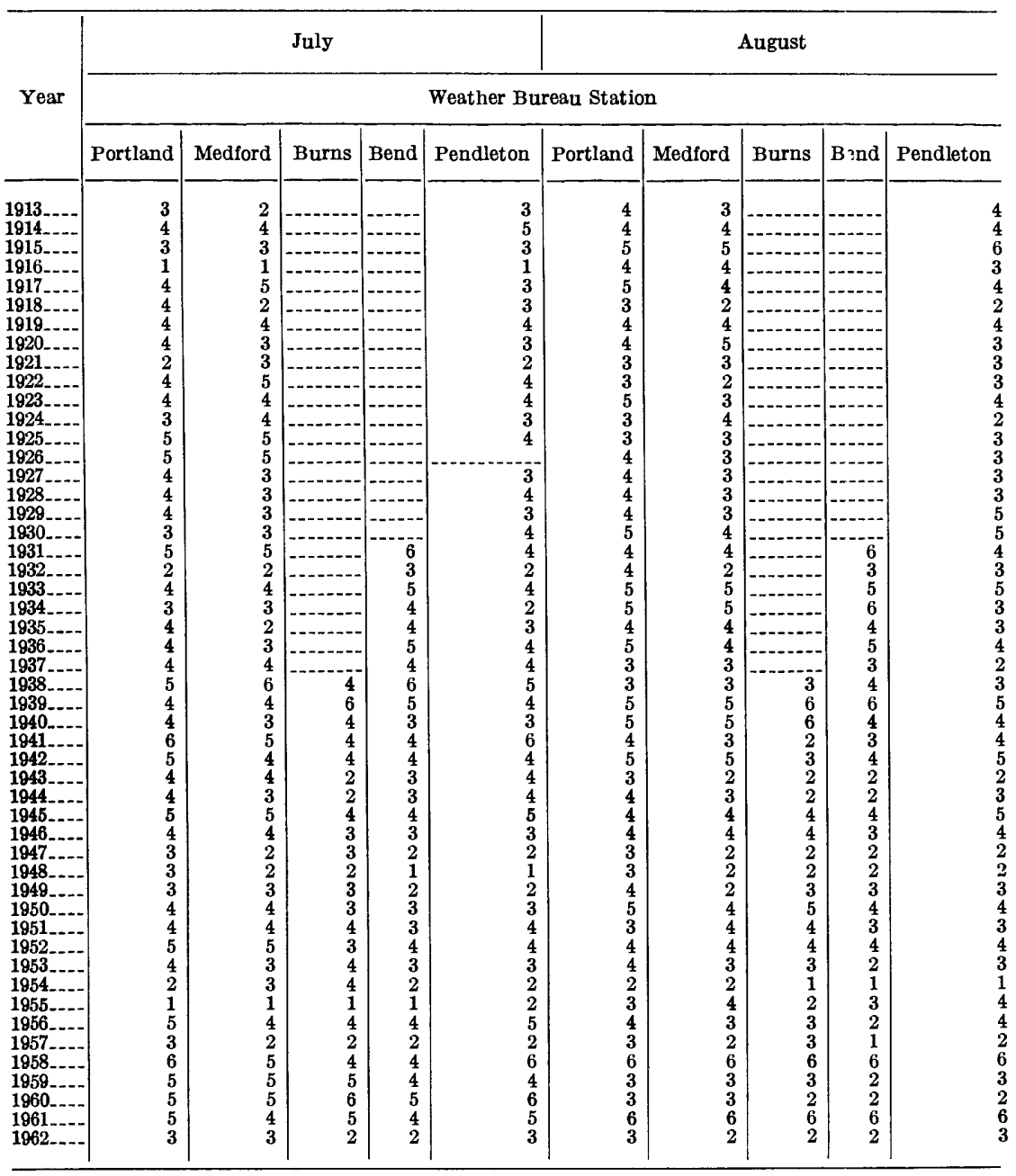

Note.-Class 1 represents air-temperature departure of $4^{\circ} \mathrm{F}$. or more below average; c'ass 2, departures between $-2^{\circ}$ and $-4^{\circ} \mathrm{F}$; class 3 , between $-2^{\circ} \mathrm{F}$. and zero; class 4 , between zero and $+2^{\circ} \mathrm{F}$; class 5 , between $+2^{\circ}$ and $+4^{\circ} \mathrm{F}$; and class 6 , departures of $+4^{\circ} \mathrm{F}$ or more. The assigned designations were shaded upward or downward if streamflow in that area departed greatly from average. The above grading therefore supplies a rough key to water temperature of streams for which solar radiation, air temperature, and amount of flow are the major factors governing water temperature.

The record for Desolation Creek was chosen for similar reasons and because it is the only long record in eastern Oregon. The record for Metolius River near Grandview was chosen because the stream is largely spring fed and the record is fairly lengthy and shculd be representative of the long-term average. For each of these three sites the departures of the various Julys and Augusts from avorage July and August water temperatures were plotted against the appropriate 

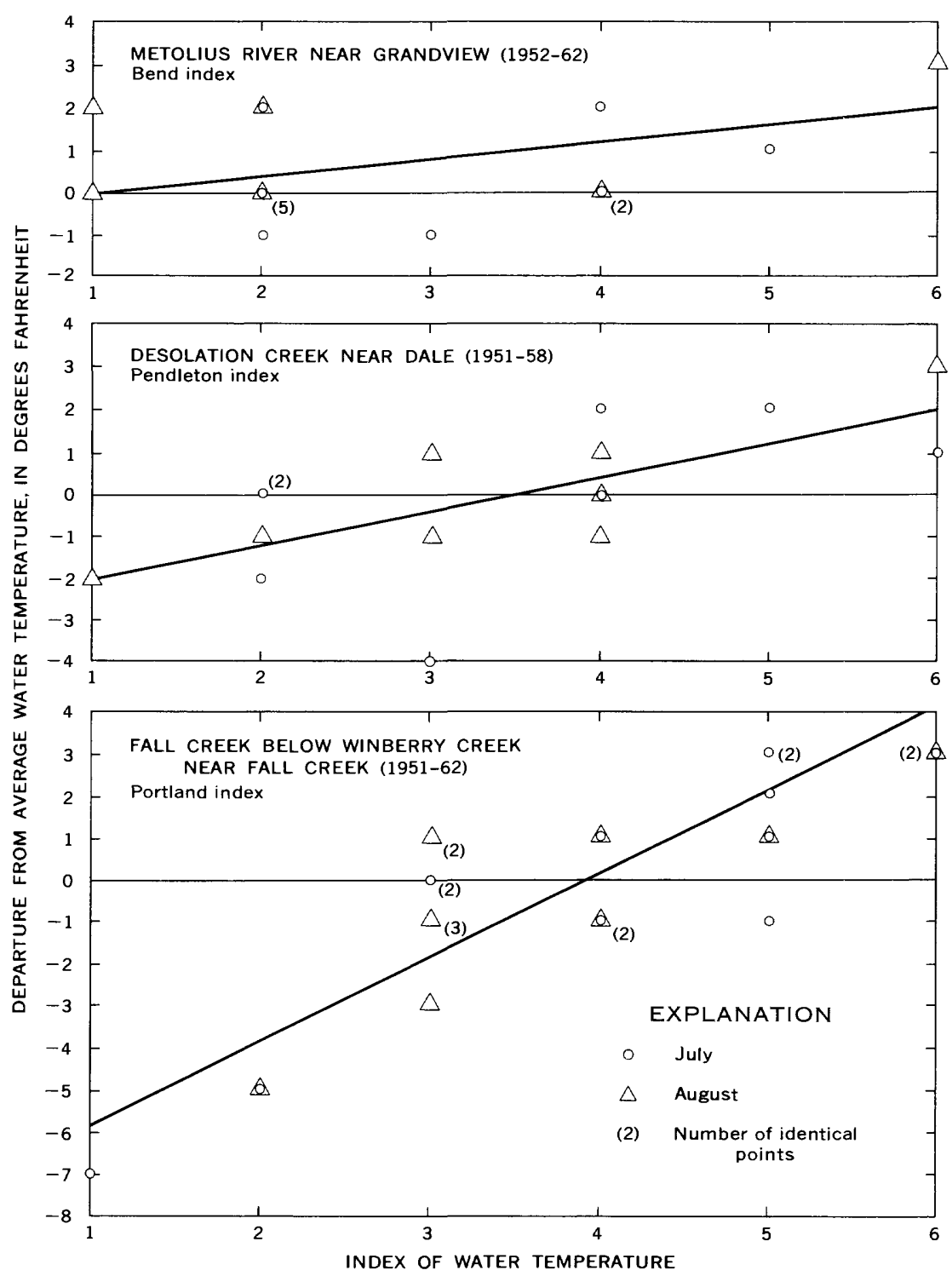

Figure 9.-Test of water-temperature classification indices for July anc August. 
index or scale of water temperatures shown in table 4. Fall Creek was plotted against the Portland index, Desolation Creek against the Pendleton index, and Metolius River against the Bend inde.x.

If the period of record for these thermograph records is perfectly representative of long-term averages, and if the computed indices are representative for the sites with which they are matched, then the plotted points can reasonably be expected to define a line that passes through zero departure from average water temperature midway between classes 3 and 4 on the index scale. Furthermore, if little else affects water temperature other than solar radiation, air temperature, and discharge, the plotted points should scatter very little. Figure 9 shows that the relation between the Portland index and Fall Creek water temperatures comes very close to this result. The relation between Desolation Creek departures and the Pendleton inder produces a line that passes through zero departure between classes 3 and 4 but is only half as steep as the line of relation for Fall Creek and the Portland index. Apparently some other factor is exerting a major influence on water temperature at that site. Possibly Desolation Creek is more shaded than Fall Creek. The correlation between Metolius River departures from average water temperature and the Rend index is the poorest of the three; in fact, there is little, if any, correlation. The slope of the line of relation is even flatter than that for Desolation Creek, and the line passes through zero departure at class 1 rather than between classes 3 and 4 . Undoubtedly, spring flow is the major factor affecting water temperature at this site. The station is close enough to the source springs that the water is always cooler than the summer air temperatures.

In summary, these tests indicate that the water-temperature indices are reliable for many streams. The moderate scattering of points for the indices of Fall Creek and Desolation Creek may indicate that one or more factors other than solar radiation, air temperature, and discharge do exert a significant influence. However, some scattering is to be expected because average water temperature and departures from average water temperature were computed only to the nearist degree, and each numerical class of the water-temperature index was chosen to represent a $2^{\circ} \mathrm{F}$. variation in air temperature. The more pronounced scattering for the Metolius River index undoubtedly is indicative of the fact that spring-flow contribution is a major factor and that the water-temperature indices are not reliable for spring-fed streams. 


\section{STATISTICAL METHOD FOR APPRAISING MONTHLY MAXIMUM AND MINIMUM WATER TEMPERATURES}

As previously stated, thermograph records for Middle Santiam River near Foster, Breitenbush River above Canyon Creek near Detroit, and Desolation Creek near Dale were the three selected to correlate with various spot-observation records made by the Gerlogical Survey throughout the State. It was evident that some of the periodof-record monthly maximums and minimums represented unusual occurrences. Furthermore, the results of these occurrences vere being transferred to the spot-observation records through the correlations. The transfer is reasonable because meteorological conditions are considered to be basically the same at the spot-observation sites as at the thermograph sites. If the probabilities of occurrence of these various maximums and minimums at the three selected thermograph sites could be established, they would furnish at least a rough estimate of the probabilities of occurrence of the adjusted maximums and minimums at the spot-observation sites.

The thermograph records by themselves are too short to allow computation of recurrence intervals for the period-of-record ertremes. However, the water temperatures can be correlated with long-term airtemperature records, and the recurrence intervals of air temperatures corresponding to the extremes of water temperature can be computed. These recurrence intervals can then be considered as applicable to the water-temperature extremes.

Portland air temperatures (record beginning in 1875) were correlated with water temperatures for Middle Santiam and Breitenbush Rivers, and La Grande air temperatures (record beginning in 1897) were correlated with water temperatures for Desolation Crefk. For both Portland and La Grande, monthly maximum air temperatures were correlated with monthly maximum water temperatures and monthly minimum air temperatures with monthly minimum water temperatures. Air temperatures corresponding to the period-of-record monthly water-temperature extremes at the thermograph sites were obtained from the correlations, and recurrence intervals for those air temperatures were computed in two ways, designated as methods 1 and 2 in table 5 . In the interest of brevity, the tabulations of air temperature, the correlation between air and water temperatures, and associated computations are not shown.

Method 1 for computing recurrence intervals consists simply of determining the number of years in which air temperature for a given month equaled or exceeded that corresponding to the period-of-record extreme of water temperature for that month. For example, from the correlation of La Grande air temperature with Desolation Creek water 
TABLE 5.-Recurrence intervals for period-of-record monthly maximum and minimum water temperatures for Desolation Creek near Dale and Middle Santiam River at mouth near Foster

\begin{tabular}{|c|c|c|c|c|c|c|c|c|c|c|}
\hline \multirow{3}{*}{ Month } & \multicolumn{5}{|c|}{$\begin{array}{l}\text { Desolation Creek } \\
\text { (eastern Oregon) }\end{array}$} & \multicolumn{5}{|c|}{$\begin{array}{l}\text { Middle Santiam River } \\
\text { (western Oreg on) }\end{array}$} \\
\hline & \multicolumn{2}{|c|}{$\begin{array}{c}\text { Temperature } \\
\left({ }^{\circ} \text { F.) }\right.\end{array}$} & \multicolumn{3}{|c|}{$\begin{array}{c}\text { Recurrence interval } \\
\text { (years) }\end{array}$} & \multicolumn{2}{|c|}{$\begin{array}{c}\text { Temperature } \\
\left({ }^{\circ} \mathrm{F} .\right)\end{array}$} & \multicolumn{3}{|c|}{$\underset{\text { ('ears) }}{\text { Recurrence interval }}$} \\
\hline & Water & Air 1 & $\underset{1}{\text { Method }}$ & $\underset{2}{\text { Method }}$ & $\begin{array}{l}\text { Aver- } \\
\text { age }\end{array}$ & Water & Air ${ }^{2}$ & $\underset{1}{\text { Method }}$ & $\underset{2}{\text { Mrethod }}$ & $\begin{array}{l}\text { Aver- } \\
\text { age }\end{array}$ \\
\hline Oct_........Max_. & 59 & 88 & 12 & 25 & 20 & 62 & 82 & 6 & 6 & \\
\hline Min & 33 & 24 & 2.5 & 2.5 & 3 & 42 & 35 & 4 & 5 & \\
\hline Min & & 65 & & & 3 & $\begin{array}{l}51 \\
37\end{array}$ & $\begin{array}{l}67 \\
22\end{array}$ & $\begin{array}{r}5 \\
22\end{array}$ & $\begin{array}{r}7 \\
30\end{array}$ & 25 \\
\hline Max & 40 & 61 & 8 & 14 & 10 & 48 & 63 & 10 & 20 & 15 \\
\hline $\operatorname{Max}_{--}$ & 37 & 56 & 4 & 5 & 5 & $\begin{array}{l}38 \\
47\end{array}$ & $\begin{array}{l}26 \\
61\end{array}$ & $\frac{2}{7}$ & $\frac{2}{7}$ & \\
\hline $\operatorname{Min}_{\text {Max }}$ & 41 & 63 & 16 & 18 & 20 & $\begin{array}{l}34 \\
48\end{array}$ & 18 & 4 & 4 & 3100 \\
\hline $\begin{array}{l}- \text { Max }_{--} \\
\text {Min }_{-}\end{array}$ & & 63 & 16 & 18 & & $\begin{array}{l}48 \\
34\end{array}$ & $\begin{array}{l}70 \\
18\end{array}$ & $\begin{array}{r}88 \\
6\end{array}$ & $\begin{array}{r}100 \\
7\end{array}$ & ${ }^{3} 100$ \\
\hline Max.- & 44 & 68 & 3 & 3 & 3 & 47 & 68 & 2 & 2 & \\
\hline Max.-. $_{\text {Man }}$ & & 80 & 3 & 2.5 & 3 & $\begin{array}{l}34 \\
54\end{array}$ & $\begin{array}{l}18 \\
82\end{array}$ & $\begin{array}{r}88 \\
3\end{array}$ & $\begin{array}{r}100 \\
4\end{array}$ & 00 \\
\hline Min.- & 33 & 24 & $\mathbf{2}$ & 2.5 & 2 & 40 & 35 & $\stackrel{\dot{2}}{2}$ & 2 & \\
\hline $\operatorname{Max}_{-}$ & 57 & 90 & 4 & 6 & 5 & 64 & 90 & 5 & 6 & \\
\hline Min.- & 33 & 24 & 21 & 33 & 25 & 41 & 37 & 6 & 7 & \\
\hline $\operatorname{Max}$ & 65 & 95 & 3 & 3 & 3 & 73 & 97 & 6 & 10 & \\
\hline Min _- & 39 & 30 & 21 & 28 & 125 & 44 & 42 & 9 & 6 & \\
\hline$-\operatorname{Max}_{\text {-. }}$ & 76 & 102 & 2.5 & 2.5 & 3 & 77 & 105 & 45 & 50 & 50 \\
\hline Min.- & 43 & 36 & 21 & 28 & 25 & 47 & 42 & 88 & 25 & 50 \\
\hline - Max & 74 & 100 & 3 & 3 & 3 & 76 & 104 & 88 & 100 & 100 \\
\hline Sept_..... Max.. & $\begin{array}{l}47 \\
66\end{array}$ & $\begin{array}{l}39 \\
96\end{array}$ & $\begin{array}{l}\mathbf{3} \\
\mathbf{5}\end{array}$ & $\begin{array}{l}2.5 \\
5.5\end{array}$ & $\begin{array}{l}\mathbf{3} \\
\mathbf{5}\end{array}$ & $\begin{array}{l}57 \\
71\end{array}$ & $\begin{array}{l}50 \\
96\end{array}$ & $\begin{array}{r}2 \\
15\end{array}$ & $\begin{array}{r}2 \\
12\end{array}$ & $\begin{array}{r}2 \\
15\end{array}$ \\
\hline Min.. & 39 & 27 & 6 & 12 & 10 & 49 & 44 & 2 & 2 & 2 \\
\hline
\end{tabular}

1 Air temperature at $\mathrm{La}$ Grande from correlation with water temperature of Des lation Creek near Dale. 2 Air temperature at Portland from correlation with water temperature of Middle Santian River at mouth near Foster.

3 Recurrence interval would be $15 \mathrm{yr}$ if, as for Desolation Creek, 1961 water temperatures were not available.

1 Recurrence interval would be $7 \mathrm{yr}$ if, as for Middle Santiam River, 1951 water temperatures were not available.

NoTe.-Computation of recurrence interval by method 1 is based on determining number of years in which air temperature was equaled or exceeded in that month Computation of recurrence interval by method 2 involves assumption of normal distribution, computation of departure from arerage in terms of standard deviation, obtaining the probability of occurrence (from theoretical normal distribution), and conversion to recurrence interval.

temperature, a May air temperature of $90^{\circ} \mathrm{F}$. was found to correspond to a water temperature of $57^{\circ} \mathrm{F}$., the period-of-record maximum water temperature for May in Desolation Creek. Inspection of the airtemperature record at La Grande showed that a May temperature of $90^{\circ} \mathrm{F}$. had been equaled or exceeded in 15 of the 65 years of record. The recurrence interval was, therefore, computed as 4 years

Method 2 for computing recurrence intervals involves the assumption that air temperatures are distributed normally. To check this assumption, maximum air temperatures at Portland for the 88 Julys from 1875 to 1962 were arrayed in order of magnitude and plotted on probability paper. The straight-line plot that resulted indicates that the assumption is reasonable. The application of the method itself is best explained by the following example. As noted under the explanation of method 1, the La Grande air temperature corresponding to maximum water temperature for May during the period of record 
at Desolation Creek was found to be $90^{\circ} \mathrm{F}$. The average of maximum May air temperatures at La Grande was computed as $85^{\circ} \mathrm{F}$. and the standard deviation as $5.1^{\circ} \mathrm{F}$. This meant that the temperature of $90^{\circ} \mathrm{F}$. differed by $+5^{\circ} \mathrm{F}$. from the average for May, or by almost exactly one standard deviation.

For a normal distribution, the probability of exceeding the average by one standard deviation is 0.16 ; therefore, the probable rec'irrence interval for maximum May air temperature of $90^{\circ} \mathrm{F}$. at La Grande (and maximum May water temperature of $57^{\circ} \mathrm{F}$. at Desolation Creek) is about 6 years.

These two methods were used to compute recurrence intervals for period-of-record monthly extremes of water temperature for Middle Santiam River and Desolation Creek except that, for the latter, recurrence intervals were not computed for the minimum from November through March, as a minimum of $32^{\circ} \mathrm{F}$. is assured.

The methods were applied to Breitenbush River extremes also, but the results are not shown because correlation was poor and computed recurrence intervals were unreasonably long. Apparently these methods are not applicable to streams with large spring-flow contributions, just as the numerical scale was found to be of little value in appraising July and August temperatures of spring-fed streams.

Recurrence intervals computed by methods 1 and 2 agree reasonably well and are combined to obtain average recurrence intervals to the nearest year below 10 and to the nearest 5 or 10 years above 10 . Agreement between recurrence intervals for period-of-record monthly extremes for the Middle Santiam River and those for Desolation Creek is not particularly close but, as shown by footnotes to table 5, would be closer in some months if the records for both sites covered the same years.

The recurrence intervals shown for July and August in table 5 lead to the conclusion that in western Oregon these extremes may ke 25- to 100 -year events, whereas in eastern Oregon the July 1955 minimum is a 25-year event, but the maximums for.July and August 1958 are not at all unusual. Earlier, inspection of the numerical scale led to the conclusion that thermograph records for July and August during the years 1955 and 1958 are representative of extremes for a 25 -year period. There is reasonable agreement between these two yardsticks.

\section{DIURNAI FLUCTUATION OF WATER TEMPERATURF}

Monthly mean water temperatures are significant data but give little indication of the wide variation in water temperature trat may occur in any given month. For that reason, the compilation report. also lists maximums and minimums for each month of each year for thermograph sites and lists period-of-record monthly maximums and 
minimums at spot-observation sites. However, even these figures do not give the complete picture as there are large diurnal fluctuations during the summer months at many sites. For spring-fed streams, the maximum daily fluctuation is generally on the order of only $2^{\circ}-$ $6^{\circ} \mathrm{F}$., but for other streams the maximum daily change may be $5^{\circ} \mathrm{F}$. to more than $20^{\circ} \mathrm{F}$. The smaller variations are likely to occur in small streams that are largely protected from direct sunlight or in large streams where the volume of water to be warmed is relatively great. The larger diurnal fluctuations occur in the more exposed streams in eastern Oregon and the inland valleys of southwestern Oregon, where summer daytime air temperature is generally high. In northwestern Oregon, the upper limit for diurnal fluctuation appears to be $13^{\circ} \mathrm{F}$. Figure 10 shows the typical summertime diurnal fluctuation of water temperature in several Oregon streams.

An unsuccessful attempt was made to devise a method for estimating the maximum diurnal water-temperature fluctuation at spot-observation sites. The approach taken was that diurnal fluctuation supplied a substantial part of the monthly water-temperature fluctuation, and that, therefore, the monthly range of water temperature, eren though obtained by correlation, should provide a rough guide to diurnal fluctuation. To test this hypothesis, maximum diurnal fluctuation of water temperature was plotted against maximum monthly rang? of water temperature during the summer months for all thermograph records. Correlation was found to exist, but record length was found to be a major factor because the period-of-record monthly temperature ranges increased substantially as the records became longer. Te method failed, largely because there were no long-term thermograph records for sites where diurnal fluctuation was large.

In lieu of a better method, maximum diurnal fluctuation at spotobservation sites can be estimated by comparison with the known fluctuation on a nearby stream. As an aid in making such estimates, table 6 lists maximum diurnal fluctuations at 129 thermograph sites. 

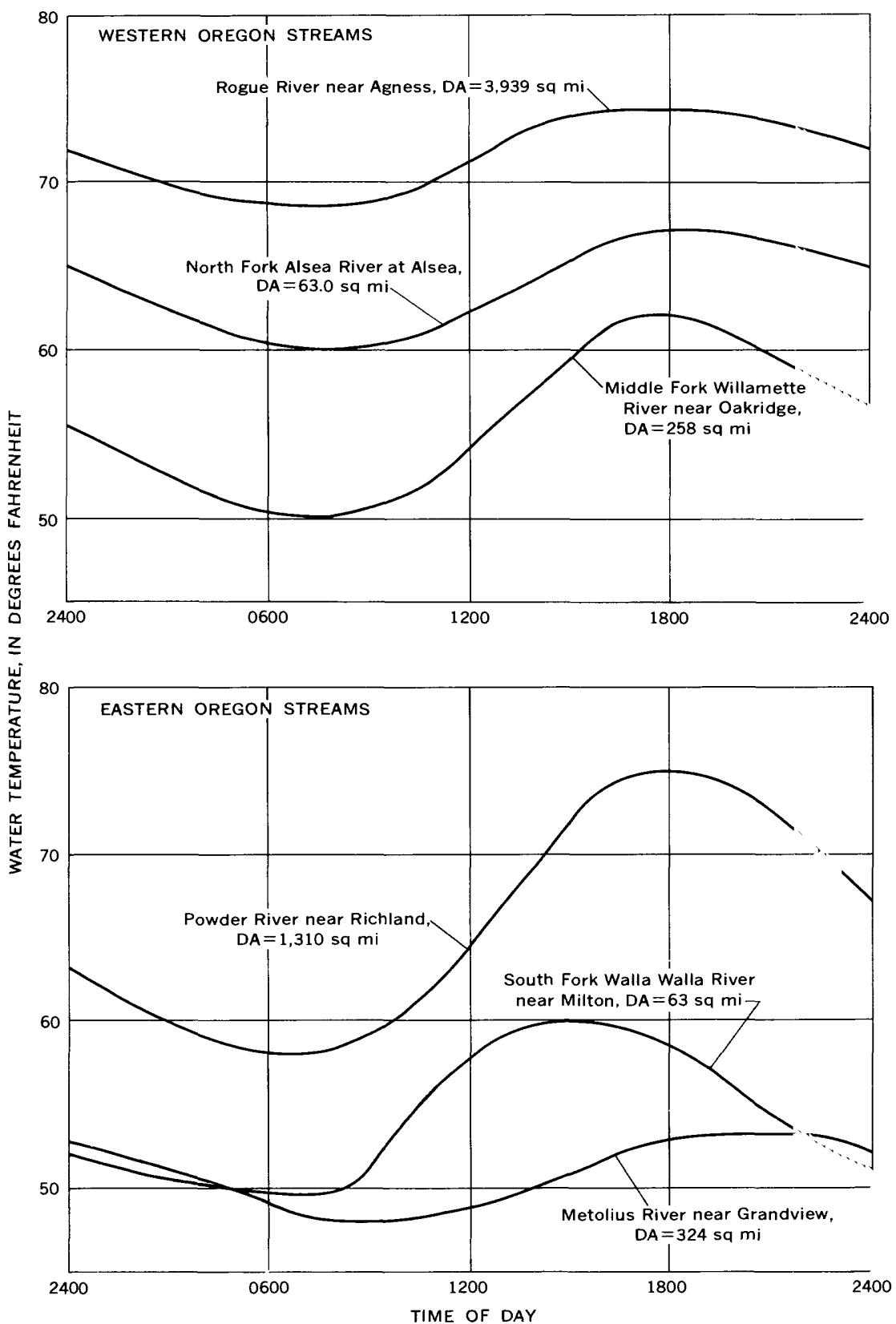

FIgURE 10.-Typical summertime diurnal fluctuation of water temperature. (DA, drainage area.) 
TABLE 6.-Maximum diurnal fuctuation of water temperature at thermograph sites

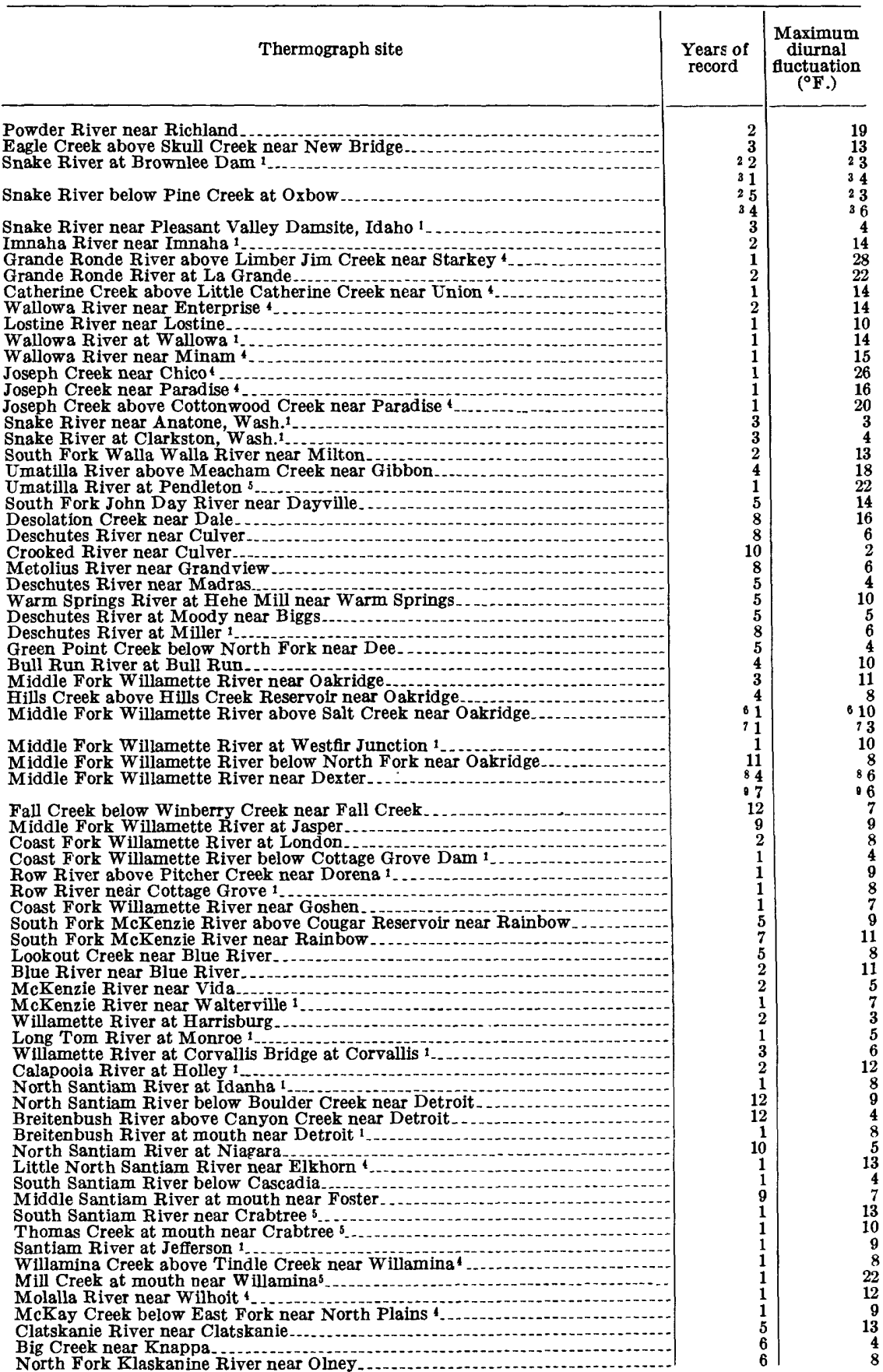

See footnotes at end of table. 
TABLE 6.-Maximum diurnal fluctuation of water temperature at thermograph sites-Continued

\begin{tabular}{|c|c|c|}
\hline Thermograph site & $\begin{array}{l}\text { Years of } \\
\text { record }\end{array}$ & $\begin{array}{l}\text { Maximum } \\
\text { diurnal } \\
\text { fluctuation } \\
\left(^{\circ} \mathrm{F} .\right)\end{array}$ \\
\hline Trask River near Tillamook ..... & 1 & 7 \\
\hline North Fork Alsea River at Alsea. & 5 & 9 \\
\hline South Fork Alsea River near Alsea & 5 & 10 \\
\hline Fall Creek near Alsea. & 2 & 8 \\
\hline Five Rivers near Fisher. & 1 & 8 \\
\hline Drift Creek near Salado. & 4 & 12 \\
\hline Needle Branch near Salado. & 4 & 4 \\
\hline Flynn Creek near Salado... & 4 & 7 \\
\hline Deer Creek near Salado. & 4 & 6 \\
\hline South Umpqua River above Jackson Creek 1 & 1 & 9 \\
\hline Jackson Creek near Tiller 1 & 2 & 12 \\
\hline South Umpqua River at Tiller 1 & 2 & 15 \\
\hline Elk Creek near Drew 1 & $\overline{1}$ & 18 \\
\hline Cow Creek near Azalea 1 . - & 2 & 16 \\
\hline Cow Creek near Riddle ${ }^{1}$ & 2 & 10 \\
\hline Myrtle Creek at Myrtle Creek & 1 & 16 \\
\hline Olalla Creek near Tenmile 1 & 1 & 19 \\
\hline South Umpqua River at Winston 1 & 2 & 24 \\
\hline North Umpqua River above Copeland Creek & 1 & 3 \\
\hline Copeland Creek at mouth near Toketee Falls ${ }^{5}$ & 1 & 8 \\
\hline Steamboat Creek near Glide 1 & 1 & 11 \\
\hline Little River at Peel 1 & & 9 \\
\hline North Umpqua River above Sutherlin Creek at Winchester 1 & 2 & 5 \\
\hline Calapooya Creek at Hinkle ${ }^{1}$ & & 5 \\
\hline Calapooya Creek near Oakland 1 - & 1 & 11 \\
\hline Umpqua River below Mehl Creek near Elkton 1 & 1 & 5 \\
\hline $\begin{array}{l}\text { West Fork Millicoma River at Devils Elbow near Allegany } \\
\text { Rock Creek near Illahe }\end{array}$ & 1 & $\begin{aligned} 15 \\
9\end{aligned}$ \\
\hline South Fork Coquille River near Powers & $\begin{array}{l}2 \\
5\end{array}$ & $\begin{array}{r}9 \\
10\end{array}$ \\
\hline Rogue River at Farewell Bend 1 & 1 & $\begin{array}{r}10 \\
7\end{array}$ \\
\hline Rogue River at Prospect 1 & 1 & 6 \\
\hline Rogue River below South Fork Rogue River near Prospect 1 & 3 & 8 \\
\hline Big Butte Creek at McLeod 1 & 1 & 11 \\
\hline Rogue River at Casey State Park at McLeod & 1 & 18 \\
\hline Elk Creek near Trail 1 & & 18 \\
\hline Rogue River at Lewis Creek near Trail 1. . & 1 & 9 \\
\hline Little Butte Creek at Eagle Point 1 & & 18 \\
\hline Rogue River at Bybee Bridge near Eagle Point & 1 & 9 \\
\hline Rogue River at Raygold near Central Point 5 & 5 & 8 \\
\hline Evans Creek near Bybee Springs 1 & 1 & 16 \\
\hline Evans Creek near Rogue River 1 ... & $\mathbf{1}$ & 18 \\
\hline Rogue River at Grants Pass $1 . . . . . .$. & & 8 \\
\hline Applegate River at Copper 1 & $\mathbf{3}$ & 19 \\
\hline Applegate River near Ruch $1 \ldots$ & 1 & 26 \\
\hline Applegate $R$ iver at mouth near Wilderville & 1 & 14 \\
\hline 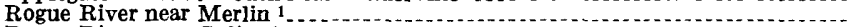 & $\overline{1}$ & 9 \\
\hline 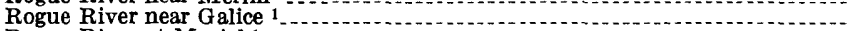 & 1 & 5 \\
\hline 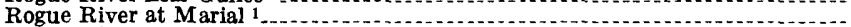 & 1 & 13 \\
\hline 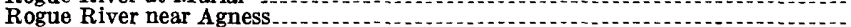 & 2 & 5 \\
\hline Rogue River at Agness 1 & $\overline{1}$ & 7 \\
\hline Illinois River above Kerby 1 & 1 & 12 \\
\hline Illinois River above Rancherie Creek near Selma & 1 & 11 \\
\hline Illinois River near Selma & 1 & 6 \\
\hline Illinois River near Agness 1 & 1 & 7 \\
\hline Rogue River near Gold Beach 1 & 1 & 8 \\
\hline Chetco River near Brookings 5 & $\overline{1}$ & 9 \\
\hline
\end{tabular}

1 Record furnished by U.S. Fish and Wildlife Service.

2 Before regulation by Brownlee Reservoir.

3 After regulation by Brownlee Reservoir.

4 Record furnished by Oregon State Fish Comm.

5 Record furnished by Oregon State Game Comm.

6 Before regulation by Hills Creek Reservoir.

7 After regulation by Hills Creek Reservoir.

8 Before regulation by Lookout Point Reservoir.

- After regulation by Lookout Point Reservoir.

NotE.-Years of record shown as 1 if there was record for 1 summer because maximum diurnal fluctuation occurs in summer months.

\section{CONCLUSIONS}

1. Spot observations and thermograph records are considere to be accurate within $1^{\circ} \mathrm{F}$. However, unless periodically checked and adjusted on the basis of hand-thermometer observaticns, the thermograph records can be as much as $3^{\circ} \mathrm{F}$. in error. 
2. Sites for water-temperature observation should be carefully selected to ensure that the water from upstream tributaries is well mixed with the main stream at the sampling site.

3. If the sensing element of the thermograph is positioned so that it is in moving water at all stages, the thermograph record will be closely representative of the water temperature in the cross section.

4. The major natural factors affecting stream temperaturs are solar radiation, shade, snowmelt contributions, tributary spring flow (amount, location, and temperature), stream dischargęe, and air temperature.

5. Cloud cover, wooded banks, steep canyon walls, and stresm orientation are the factors providing shade and corresponding reduction in water temperature. Of the last three, stream oriontation is probably the most important.

6. During the summer months the mean temperature of some streams is warmer than the mean air temperature; for others it is cooler. North-south orientation and spring-flow contributions are the major natural factors that cause water temperatures to be cooler than air temperatures during the summer months.

7. Spot observations of water temperature, if date and time of observation are known, can be correlated with a thermogre ph record. Usually the correlation is not constant throughout the year but changes monthly or seasonally. The standard error of estimates from such correlations is generally $1^{\circ}-2^{\circ} \mathrm{F}$.

8. For streams that are not spring fed, the period-of-record means and extremes of water temperature, as obtained from spot observations for each of the 12 calendar months, averag about $2^{\circ}$ and $4^{\circ} \mathrm{F}$. in error, respectively, and the correlations reduce these errors by 50 percent or more. For spring-fed streems, water temperature varies so little that correlation cannot improve the accuracy of the observed means. However, correlation procedures do result in some improvement in the monthly extremes, particularly where the spot-observation record is for only a few years.

9. Thermograph records for July and August in western Oregon that include the years 1955 and 1958 are representative of extremes with expected recurrence intervals of at least 25 years.

10. Maximum diurnal water-temperature fluctuations in Oregon streams that receive substantial spring-flow contributions range from about $2^{\circ}$ to $6^{\circ} \mathrm{F}$. In streams that are not spring fed, the maximum diurnal fluctuation generally ranges from $5^{\circ}$ to $20^{\circ}$ F. The smaller variations occur in shaded streams or in large 
streams where the volume of water to be heated or cooled is relatively great. The larger fluctuations occur in the more exposed streams of eastern Oregon and in the inland valleys of southwestern Oregon, where summer daytime air temperatures are generally high. In northwestern Oregon the upper limit for diumal fluctuation appears to be about $13^{\circ} \mathrm{F}$.

11. The major factors governing the effect of reservoirs on downstream water temperatures are the volume and depth of impounded water, the depth at which water is withdrawn, and the amount of release as compared to the natural or unregulated flow.

12. Spot observations of water temperature several miles or more below a reservoir are uniquely suited to assessing the effect of the reservoir on stream temperature if they are made before and after construction of the reservoir and if a nearby thermograph record on an unregulated strean is also available for the same periods. When these conditions exist, both the "before" and "after" records can be correlated with the thermograph record to obtain estimates of the mean monthly water temperature: for the period of record at the thermograph site. Thus, both correlations give estimates for the same period, but one excludes and the other includes the effect of the reservoir.

13. The effect of reservoirs can extend for many miles downstream, but as the releases move downstream there may be a skewing of the cooling or warming effects because of changes in flow pattern or temperature gradients from the flows and gradients that existed under natural, unregulated conditions.

\section{REFERENCES}

Collins, W. D., 1925, Temperature of water for industrial use: U.S. Geol. Survey Water-Supply Paper 520-F, p. 97-104.

Mangan, J. W., 1946, Temperatures of natural waters in Pennsylvania : Commonwealth of Pennsylvania, Dept. Forest and Waters Rept., $222 \mathrm{p}$.

Meyer, A. F., 1928, Elements of hydrology : New York, John Wiley \& Sons, 552 p.

Moore, A. M., 1957, Measuring streamflow under ice conditions : Am. Soc. CiviI Engineers Proc., HY 1162, 12 p.

— 1964, Compilation of water-temperature data for Oregon stres.ms: U.S. Geol. Survey open-file report, $134 \mathrm{p}$.

Sylvester, R. O., 1963, Effects of water uses and impoundments on water temperature, in Water temperature-influences, effects and control, Froc. 12th Pacific Northwest Symposium on Water Pollution Research: U.S. Public Health Service. Pacific Northwest Water Lab., p. 6-27.

Ward, J. C., 1963, AnnuaI variation of stream water temperature : Am. Soc. Civil Engineers Proc., SA 3710, 16 p. 


\section{Contributions to the}

\section{Hydrology of the}

United States, 1965

GEOLOGICAI, SURVEY WATER-SUPPLY PAPER 1819

This volume was published

as separate chapters $A-K$

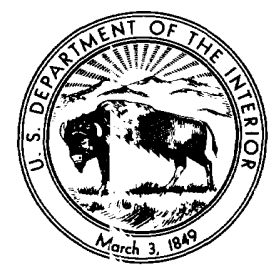


UNITED STATES DEPARTMENT OF THE INTERIOR STEWART L. UDALL, Secretary

\section{GEOLOGICAL SURVEY}

William T. Pecora, Director 


\section{CONTENTS}

[Letters designate the separately published chapters]

(A) Utilization of ground water in the Santa Maria Valley area, California, by G. A. Miller and R. E. Evenson.

(B) Predicted hydrologic effects of pumping from the Lichterman well field in the Memphis area, Tennessee, by Dale J. Nyman.

(C) Summary of hydrologic conditions of the Louisville area, Kentucky, by Edwin A. Bell.

(D) Water resources of Fort Huachuca Military Reservation, southeastern Arizona, by S. G. Brown, E. S. Davidson, L. R. Kister, and B. W. .'.homsen.

(E) Salinity of the ground water in western Pinal County, Arizona, by L. R. Kister and W. F. Hardt.

(F) Recharge studies on the high plains in northern Lea County. New Mexico, by John is. Havens.

(G) Water-quality characteristics of New Jersey streams, by Peter W. Anderson and John R. George.

(H) Fluvial sediment and chemical quality of water in the Little Bl"o River basin, Nebraska and Kansas, by James C. Mundorff and Kidd M. Waddell.

(I) Ground-water development in the High Plains of Colorado, by Arnold J. Boettcher.

(J) Special sediment investigations, Mississippi River at St. Louis, Missouri, 1961-63, by Cloyd H. Scott and Howard D. Stephens.

(K) Correlation and analysis of water-temperature data for Oregon streams, by A. M. Moore. 


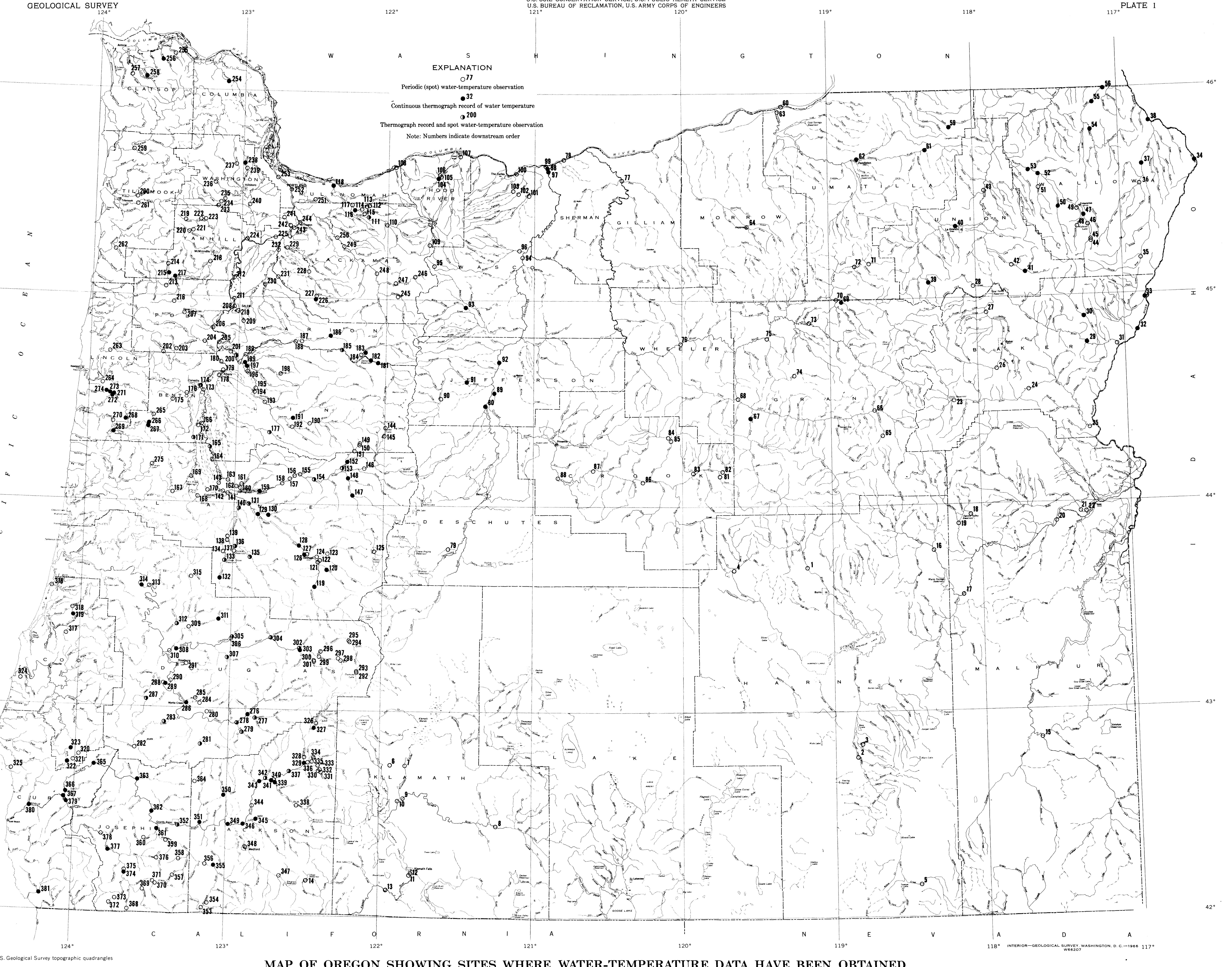

MAP OF OREGON SHOWING SITES WHERE WATER-TEMPERATURE DATA HAVE BEEN OBTAINED 